\title{
The influence of light on thermal responses
}

Citation for published version (APA):

te Kulve, M., Schellen, L., Schlangen, L. J., \& van Marken Lichtenbelt, W. D. (2016). The influence of light on thermal responses. Acta Physiologica, 216(2), 163-185. https://doi.org/10.1111/apha.12552

Document status and date:

Published: 01/02/2016

DOI:

10.1111/apha.12552

Document Version:

Publisher's PDF, also known as Version of record

Document license:

Taverne

\section{Please check the document version of this publication:}

- A submitted manuscript is the version of the article upon submission and before peer-review. There can be important differences between the submitted version and the official published version of record.

People interested in the research are advised to contact the author for the final version of the publication, or visit the DOI to the publisher's website.

- The final author version and the galley proof are versions of the publication after peer review.

- The final published version features the final layout of the paper including the volume, issue and page numbers.

Link to publication

\footnotetext{
General rights rights.

- You may freely distribute the URL identifying the publication in the public portal. please follow below link for the End User Agreement:

www.umlib.nl/taverne-license

Take down policy

If you believe that this document breaches copyright please contact us at:

repository@maastrichtuniversity.nl

providing details and we will investigate your claim.
}

Copyright and moral rights for the publications made accessible in the public portal are retained by the authors and/or other copyright owners and it is a condition of accessing publications that users recognise and abide by the legal requirements associated with these

- Users may download and print one copy of any publication from the public portal for the purpose of private study or research.

- You may not further distribute the material or use it for any profit-making activity or commercial gain

If the publication is distributed under the terms of Article $25 \mathrm{fa}$ of the Dutch Copyright Act, indicated by the "Taverne" license above, 


\title{
REVIEW
}

\section{The influence of light on thermal responses}

\author{
M. te Kulve,' L. Schellen, ${ }^{1,2}$ L. J. M. Schlangen ${ }^{3}$ and W. D. van Marken Lichtenbelt' \\ I Department of Human Biology, NUTRIM, Maastricht University, Maastricht, the Netherlands \\ 2 School of Built Environment and Infrastructure, Avans University of Applied Sciences, Tilburg, the Netherlands \\ 3 Philips Research, Philips, Eindhoven, the Netherlands
}

Received 6 March 2015,

revision requested 2 July 2015 , accepted 3 July 2015

Correspondence: M. te Kulve, Department of Human Biology, NUTRIM, Maastricht University, Universiteitssingel 50, Maastricht 6229 ER, the Netherlands. E-mail: m.tekulve@maastricht university.nl

\begin{abstract}
Light is essential for vision and plays an important role in non-visual responses, thus affecting alertness, mood and circadian rhythms. Furthermore, light influences physiological processes, such as thermoregulation, and therefore may be expected to play a role in thermal comfort (TC) as well. A systematic literature search was performed for human studies exploring the relation between ocular light exposure, thermophysiology and TC. Experimental results show that light in the evening can reduce melatonin secretion, delay the natural decline in core body temperature (CBT) and slow down the increase in distal skin temperature. In the morning though, bright light can result in a faster decline in melatonin levels, thus enabling a faster increase in CBT. Moreover, the colour of light can affect temperature perception of the environment. Light with colour tones towards the red end of the visual spectrum leads to a warmer perception compared to more bluish light tones. It should be noted, however, that many results of light on thermal responses are inconclusive, and a theoretical framework is largely lacking. In conclusion, light is capable of evoking thermophysiological responses and visual input can alter perception of the thermal environment. Therefore, lighting conditions should be taken into consideration during thermophysiological research and in the design of indoor climates.

Keywords circadian rhythm, indoor environment, light, physiology, thermal comfort, thermoregulation.
\end{abstract}

\section{Introduction}

Lighting conditions are known to be important for visual comfort (Carlucci et al. 2015) during tasks such as writing, reading and working at a computer (Veitch et al. 1991, Newsham et al. 2005). However, light also plays an important role in non-visual responses that are mediated via the eyes. Studies show that depending on the intensity and the spectral composition of the light exposure, light has important nonvisual effects on cognition, the sleep-wake cycle, mood, health and alertness of man (e.g. Küller \&
Wetterberg 1993, Knez 1995, van Bommel \& van den Beld 2004, Webb 2006, Cajochen 2007, Manav 2007, Smolders et al. 2012, Shamsul et al. 2013, LeGates et al. 2014). Light synchronizes our circadian body clock to the environmental light-dark cycle. Thermophysiological processes are known to have a circadian rhythm; therefore, light may also affect human thermal responses via circadian photoentrainment. Due to the increasing amount of artificial light that people are exposed to during the evening and at night, the sleep-wake rhythm can become disturbed. The effects of circadian disruption on human physiology and 
health are not yet fully understood (Falchi et al. 2011, LeGates et al. 2014), but there are clear indications that circadian disruptions compromise human health and functioning. Long-term circadian rhythm disruption has negative health effects and is a risk factor for cancer, cardiovascular disease, metabolic abnormalities and impairments of the immune system (Pritchett et al. 2012). Additionally, studies found a link between circadian rhythm disruption and mental illness (Jagannath et al. 2013). Temperature and lighting conditions are important instruments that can be used to enhance comfort in indoor environments, thus contributing to stress reduction and improved well-being (Donald \& Siu 2001).

However, to the best of our knowledge no review is available about the effects of ocular light exposure on thermophysiology and thermal comfort (TC). Therefore, this literature review aimed to structure studies relating lighting conditions, thermophysiology and TC. First, the theoretical background of the possible physiological interaction between light and thermal responses will be described. Next, the methodology of the literature search will be explained. Subsequently, studies about the effects of light on (thermo)physiological responses and finally on the subjective responses will be described and discussed. Together this yields a better understanding of the interaction between light and human thermal responses.

\section{Background on light and light perception}

In this section, the perception of light and sensitivity of the human eye to light will be explained. The pathways that carry light information will be discussed together with the pathways involved in thermal responses. Connections between these two processes will be explored in an attempt to understand or explain effects of light on thermophysiology or TC.

\section{Physics of light}

Light is electromagnetic radiation and can convey visual information by stimulating receptors in the human eye (Mather 2009). The visible light spectrum ranges from approx. $380-780 \mathrm{~nm}$, as illustrated in Figure 1 (Boyce 2003). For a white light source, containing all wavelengths within the visible spectrum, the colour temperature can be used to denote the spectral properties of the source. The colour temperature represents the radiant temperature of a black body radiator that emits a spectrum that, for human colour perception, is virtually identical to the spectrum of the white light source. The radiation of a black body consists of all wavelengths from 0 to $\infty$ and has a peak at a particular wavelength $(\lambda)$. The

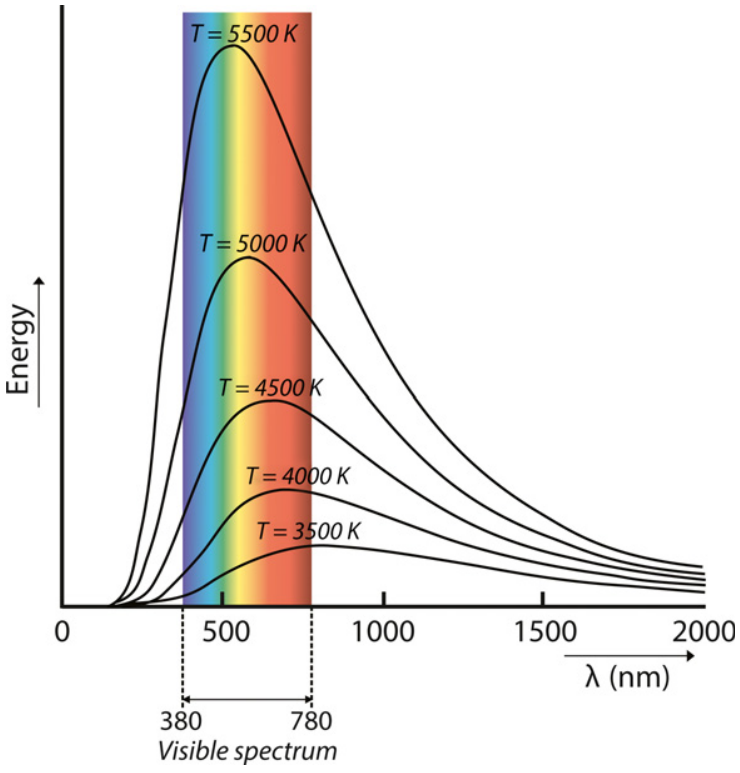

Figure I The electromagnetic spectrum emitted by an ideal black body radiator emitting at different radiant temperatures. The visible range of the spectrum is also indicated in the figure (black body spectrum obtained from Ranganath 2008).

temperature of the black body determines the wavelength of this peak: a higher temperature goes along with a peak at shorter wavelengths (Ranganath 2008). Figure 1 shows the spectrum of a black body radiator emitting at different radiant temperatures, denoted as the colour temperature and expressed in Kelvin (K), within the range of 3500-5500 K. It can be observed that the spectrum of an emitter with a colour temperature of $5500 \mathrm{~K}$ has a peak at shorter wavelengths (green and blue colours) compared to an emitter with a colour temperature of $3500 \mathrm{~K}$ that contains more wavelengths towards the red end of the spectrum. An incandescent light bulb generates thermal radiation in the form of light that is emitted from a filament. The bulb approximates an ideal black body radiator, and the colour temperature of the lamp is essentially the temperature of the filament. However, many light sources generate light by means of mechanisms different than thermal radiation, for example light emitting diodes and fluorescent lamps (Bellia et al. 2011). Consequently, the emitted radiation does not fully match the spectral properties of a black body radiator. Therefore, the term correlated colour temperature (CCT) is often used describe the spectral properties of such a white light source.

\section{Sensitivity of the human eye}

Light energy received by the eyes is converted in neuronal activity by photoreceptor cells in the retina. 
Rods and cones are the two classical photoreceptor cells in the eye (Berson 2003). Rods are responsible for vision at low lighting intensities, while the red, blue and green cones provide colour vision. These photoreceptors all contribute to information for the visual system. However, the response of the human eye to light is not the same for different wavelengths within the visible spectrum. The spectral luminous efficiency function specifies the relative sensitivity of ocular vision for different wavelengths. At high light levels, the sensitivity is represented by the photopic curve $\mathrm{V}(\lambda)$. This is the combined sensitivity of the three cones and has a peak sensitivity at $555 \mathrm{~nm}$ (Bellia \& Bisegna 2013). The scotopic curve, V'( $\lambda)$, represents the sensitivity of the eye at lower light levels, obtained by rods, and is most sensitive at $507 \mathrm{~nm}$ (Bellia \& Bisegna 2013). These sensitivity curves are illustrated in Figure 2. The cone and rod photoreceptors dominate photopic and scotopic vision respectively. There is a third type of photoreceptor in the retina of the human eye that has been discovered more recently; the melanopsin-containing photosensitive retinal ganglion cell (pRGC). These cells play an important role in the synchronization of the circadian rhythm (Berson 2003). Via this photoentrainment, light indirectly influences behaviour, sleep, cognition, seasonal affective disorders, melatonin production, cortisol production and core body temperature (CBT) (Lucas et al. 2014). The pRGCs are most sensitive to wavelengths of $480 \mathrm{~nm}$ (Lucas et al. 2014) but also receive input from rods and cones. The sensitivity curve of pRGCs, $\mathrm{Nz}(\lambda)$, is illustrated in Figure 2.

Next to radiometric units (such as $\mathrm{W} \mathrm{m}^{-2}$ ), photometric units are often used to describe lighting conditions. For instance, the illuminance of light is often expressed in (photopic) lux, which is equivalent to $\mathrm{W} \mathrm{m} \mathrm{m}^{-2}$ adjusted for the sensitivity of the human eye for light of different wavelengths. Photometric units are obtained when corresponding units in the radiometric system are adjusted for the sensitivity of the eye for photopic vision $(\mathrm{V}(\lambda)$ ) (Bellia \& Bisegna 2013). The photometric units are adjusted for vision but do not address the circadian effect, as the spectral sensitivity for circadian effects via the pRGCs $(\mathrm{Nz}(\lambda))$ is different. The response of the pRGCs to light is slower than that of rods and cones (Berson 2003). However, bright light can evoke a sustained depolarization in the pRGCs (Berson et al. 2002). Earlier studies already demonstrated that the effect of light on the circadian timing depends on the light dose; that is, different exposure durations resulted in different circadian phase-shifting effects (Zeitzer et al. 2000). The effect of the duration of the lighting exposure on the circadian phase shift appeared to be nonlinear; per minute of lighting exposure, short exposures are more efficient as compared to longer lighting exposures (Chang et al. 2012). This effect of the duration of light may be different for thermal responses, but possible saturation properties should be taken into account when interpreting the results of the studies discussed in the next sections.

\section{Visual and non-visual pathways activated by light}

Figure 3 illustrates the neural pathways that can be activated by ocular light exposure (L). The photoreceptor cells (pRGCs, rods and cones) of the eye receive light. As described, the rods and cones provide input that is translated into visual information. The pRGCs are, inter alia, connected to the suprachiasmatic nucleus (SCN) of the hypothalamus (Berson et al. 2002). The SCN coordinates the circadian rhythms of a wide range of behavioural and physiological processes (Leglise 2008). The pRGCs are important for non-visual biological effects such as circadian timing of body temperature, heart rate (HR), cortisol production, melatonin production and alertness (van Bommel 2006, Lucas et al. 2014). The
Figure 2 The sensitivity curves for the human photoreceptors: the photopic curve $\mathrm{V}(\lambda)$ as defined by the cone photoreceptors and the scotopic curve $\mathrm{V}^{\prime}(\lambda)$ as defined by the rods, and the estimated sensitivity curve of the melanopsin-containing pRGCs is displayed by $\mathrm{Nz}(\lambda)$. Data obtained from 'Irradiance toolbox' (Lucas et al. 2014).

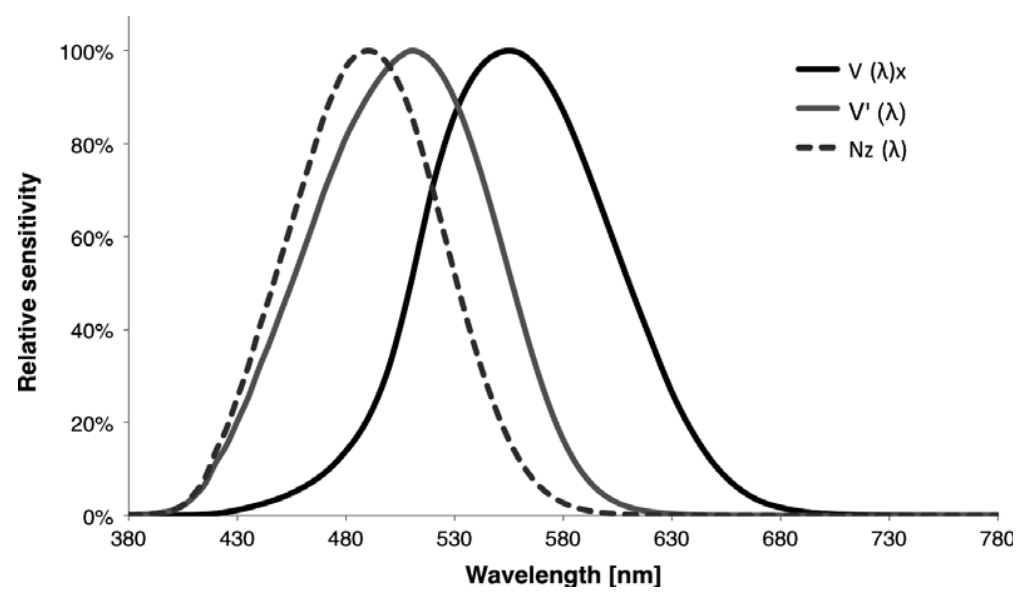




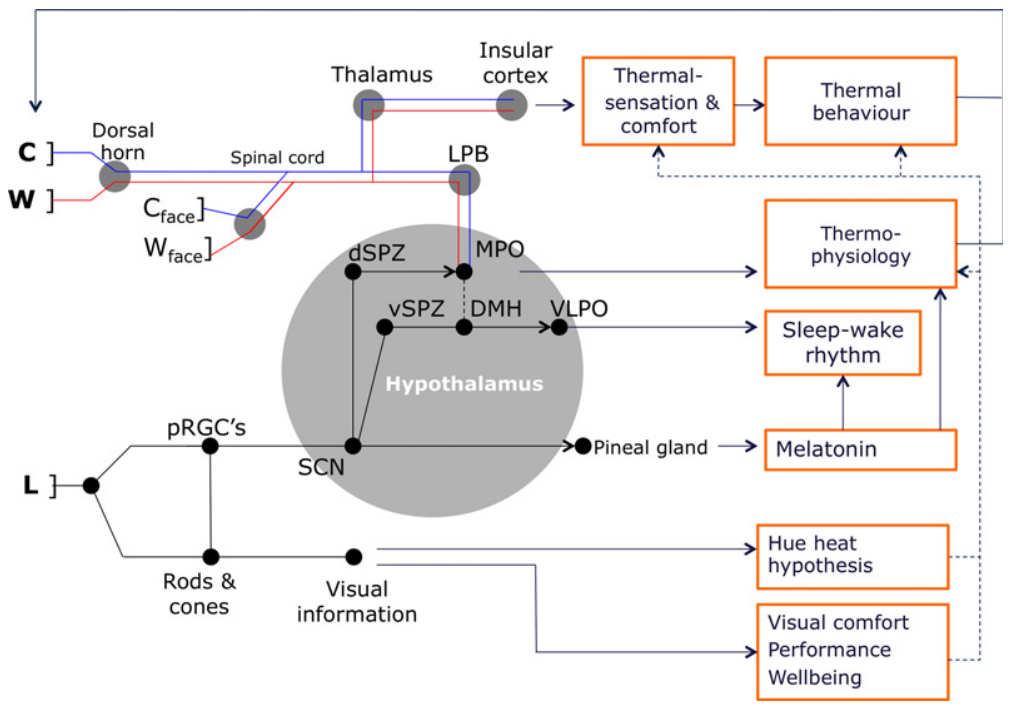

Figure 3 Neural pathways for temperature information via the cold-sensitive neurones ' $\mathrm{C}$ ' and the warm-sensitive neurones ' $W$ ' and the neural pathways of light ' $L$ '. The possible relation between visual information and thermoregulatory responses, thermal sensation and behaviour is indicated with a dashed line.
pRGCs are sensitive to light themselves, but also receive input from the rods and cones (Lucas et al. 2014). Additionally, pRGCs might transmit information directly to visual pathways as well (Hatori \& Panda 2010).

\section{Neural pathways activated by the thermal environment}

The upper part of Figure 3 illustrates how cold (C) or warm (W) temperatures lead to thermophysiological responses and perception of the temperature. Thermal receptors are located in the skin; in the internal body, for example intestines and blood vessels; and in the hypothalamus. The skin contains warmth receptors that have a peak response around $40{ }^{\circ} \mathrm{C}$ and cold receptors that are most responsive to temperatures around $20^{\circ} \mathrm{C}$ (Zigmond et al. 1999). The fire rate of the receptors is temperature dependent. The receptors project to the thermal sensory neurones in the dorsal horn. These signals are redirected via the spinal cord and transmitted, among others, to the thalamus (Morrison \& Nakamura 2011). Here, these signals are sent to the insular cortex (Craig et al. 2000), which is involved in the thermal perception and temperature sensing at high spatial resolution (Romanovsky 2007, Morrison \& Nakamura 2011), resulting in thermal sensation (TS) and TC, and could influence thermal behaviour.

The thermosensory signals are also transmitted from the lateral parabrachial nucleus to the medial preoptic area (MPO) of the hypothalamus. The MPO is involved in heat dissipation by coordinating the autonomic nervous system (Martin 2003). The coldinduced signals activate mechanisms for cold defence such as cutaneous vasoconstriction, non-shivering thermogenesis in the brown adipose tissue (BAT), and shivering heat production in the skeletal muscle. On the other hand, warm-sensitive neurones inhibit these activities. They promote heat loss and can induce cutaneous vasodilation and evaporative cooling through sweating (Morrison \& Nakamura 2011).

The SCN is also involved in thermoregulation, and it plays an important role in controlling the circadian rhythm of CBT (Scheer et al. 2005) and energy expenditure (EE) (heat production) (Coomans et al. 2013b). Experimental results suggest that the dorsomedial nucleus of the hypothalamus (DMH) and MPO receive signals from the $\mathrm{SCN}$ and may provide input to the ventrolateral preoptic area (VLPO) (Deurveilher et al. 2002). According to Saper et al. (2005), these signals from the SCN are sent via the dorsal subparaventricular zone to the MPO, which is responsible for the circadian rhythm of thermoregulation. The SCN also provides input to the ventral subparaventricular zone, which integrates these signals together with other stimuli, in the DMH. The DMH projects these signals to the to the VLPO, which is important in the control of the sleep-wake rhythm (Saper et al. 2005). The DMH may also play a role in thermoregulation (Dimicco \& Zaretsky 2007).

The neural pathways that are activated by light and temperature are combined in one model to show the potential connections between the visual and thermal responses. Figure 3 reveals that both systems share the hypothalamus. However, the different pathways are connected to different nuclei in the hypothalamus. The thermal pathway is connected to the MPO, while the pathway of light is connected to the SCN. Still, the circadian rhythm of thermoregulation requires integration of the input of the SCN about circadian timing. Therefore, light can affect thermoregulation, which on its turn could alter TS and TC. Apart from the phase-shifting effect, other physiological or 
psychological connections between the visual system and thermal system can lead to light-induced thermal responses, as described in the next sections.

\section{Circadian effects and the role of melatonin}

Light influences the circadian system and the timing of our body clock. Melatonin is an important marker of the circadian timing system. It is only secreted during the habitual sleep period and enables for consolidated sleep (Dijk et al. 1997). When it is sufficiently dark during the habitual sleep period of diurnal species, the firing activity of the SCN is low and melatonin is secreted by the pineal gland. Light during the habitual sleep period, in man this usually is at night, increases the SCN firing activity and suppresses the release of melatonin (Gonnissen 2013). The amount of melatonin suppression depends on the spectrum of the light exposure (Brainard et al. 2001, Thapan et al. 2001), but also depends on the timing of the exposure and the prior light history; melatonin suppression is larger when the lighting exposure is preceded by dim light instead of bright light (Chang et al. 2011). Melatonin is involved in the dissemination of information about the daily light-dark cycle to the body physiology (Cardinali \& Pevet 1998). Light can acutely suppress melatonin production, and it can also shift melatonin production (and sleep) to later and earlier times, depending on whether the light exposure occurs in the hours before or after the time point of the lowest CBT (Dijk et al. 1995).

Melatonin has a circadian rhythm with high levels and a peak during our habitual sleep period (during the night for most people), and very low levels during the habitual wake period (during the day for most people; Fig. 4a). The circadian rhythms of several thermo-
Figure 4 (a) Data of CBT and melatonin concentration obtained by Cajochen et al. (1999) in men under sustained wakefulness of $32 \mathrm{~h}$ (Cajochen et al. 1999); (b) heat production data obtained by Krauchi \& Wirz-Justice (1994) in men under unmasking conditions (constant bed rest, no sleep, regular food and fluid, lighting intensity of $<50$ lux and temperature of $22{ }^{\circ} \mathrm{C}$ ) (Krauchi \& Wirz-Justice 1994); (c and d) distal and proximal skin temperature and CBT data obtained by Krauchi et al. (2000), 7.5-h constant routine (16:3024:00 hours), followed by 7.5-h sleep period (24:00-7:30 hours) (Krauchi et al. 2000).
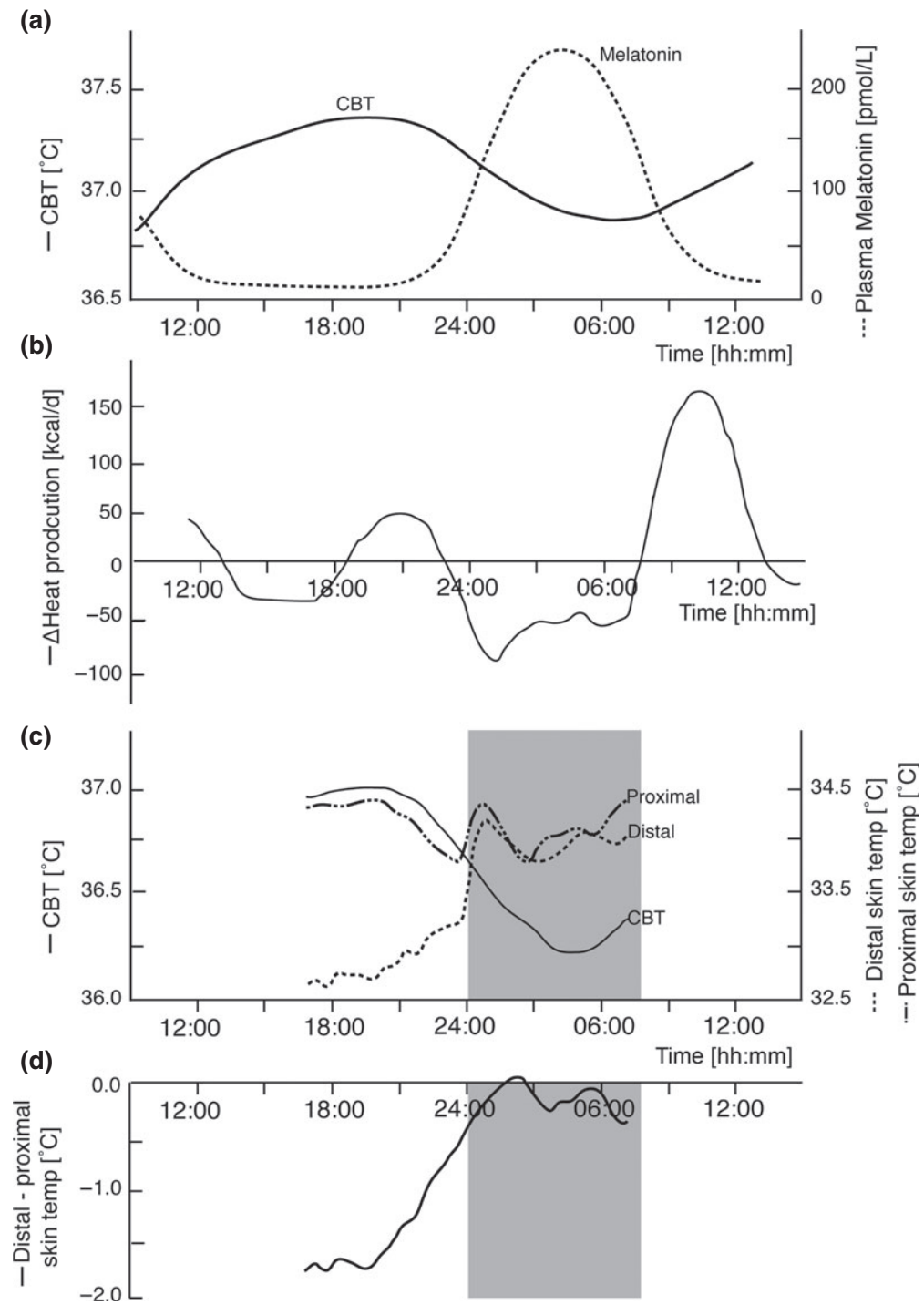
physiological parameters are shown in Figure 4. Figure $4 \mathrm{~b}$ and $\mathrm{c}$ illustrates that in the evening, there is an increase in distal skin temperature (SKT) and a decrease in heat production, proximal SKT and CBT (Aschoff 1983, Krauchi \& Wirz-Justice 1994). Melatonin is associated with an increase in sleepiness, decrease in rectal temperature and proximal body temperature in humans (Deacon et al. 1994). The relation between melatonin, CBT and SKTs was also confirmed by means of oral melatonin administration. Administering melatonin resulted in an increase in distal SKT, while proximal and CBT reduced (Krauchi et al. 2006). The reduction of the distal to proximal SKT gradient (DPG) suggests that melatonin induces vasodilation (van der Helm-van Mil et al. 2003, Krauchi et al. 2006). Higher distal temperatures are associated with a rapid onset of sleep (Krauchi et al. 1999, Lack et al. 2008). Thus, melatonin influences thermoregulation by heat loss induction (vasodilation) (Gilbert et al. 1999, Cajochen et al. 2003, PandiPerumal et al. 2008), thereby increasing distal temperatures and decreasing CBT. In the early morning, exogenous melatonin administration results in a phase delay, while in the evening, it results in a phase advance (Arendt \& Skene 2005).

Besides affecting the rhythm of thermoregulation, melatonin seems to be important for an adequate energy balance and the regulation of EE through activating BAT (Cipolla-Neto et al. 2014). In rodents, injection of melatonin increases BAT activity (Saarela \& Reiter 1994, Cipolla-Neto et al. 2014). Also nocturnal locomotor activity in rats was increased after melatonin administration, which resulted in decreased body weight, as it did not influence food intake (Terron et al. 2013). However, the effect of melatonin in humans could be the opposite because melatonin typically reinforces dark-period-related behaviour within each species; this means waking in nocturnal hamsters or rat and sleeping in the diurnal species such as man (Huber et al. 1998). In man, the heat production declines when melatonin increases in the evening. Although functional BAT has been described in adult humans as well (e.g. van Marken Lichtenbelt et al. 2009), the effect of melatonin on EE in humans remains to be explored.

In conclusion, light is important in regulating the circadian rhythm, thus controlling thermophysiological rhythms such as those of the CBT and SKTs. The SCN is responsible for these physiological effects and regulates the secretion of melatonin, which in turn also affects thermophysiological responses. However, it cannot be concluded that altering the circadian timing is the only mechanism to affect thermal responses. Other mechanisms, such as the psychological effect of visual information or acute alerting effects of light, which will be described more extensively below, may be involved. The next sections describe studies that tested the effect of lighting conditions on human (thermo)physiological responses and on TC.

\section{Systematic review on the effects of light on thermal responses}

\section{Publications search}

A systematic literature search was performed to collect studies on the relation between light, thermophysiology and TC. The electronic databases that were used are Science Direct, PubMed and Web of Science, and Google Scholar was used as a search system. A combination of the terms from I and II was used: (I) 'thermal comfort' or 'thermal sensation' or 'thermoregulation' or 'thermophysiology' or 'thermal behaviour' or 'dressing behaviour' or 'core-temperature' or 'skin-temperature' or 'human energy expenditure' or 'blood perfusion' and (II) 'light' or 'bright' or 'dim' or 'colour' or 'illuminance' or 'visual'. Additionally, publications were found from the references from other articles.

Selection of the articles was made based on title and/or abstract. Inclusion criteria were peer-reviewed studies in humans about the effects of visual input on thermophysiology and/or TC. The physiological parameters that are included are core body temperature (CBT), skin temperatures (SKT), distal to proximal skin temperature gradient (DPG), distal to core temperature gradient (DCG), blood flow (BF), sweat $(\mathrm{SW})$, energy expenditure (EE), heart rate (HR) and blood pressure (BP). For thermal comfort, the parameters thermal comfort (TC), thermal sensation (TS), preferred temperature (PT) and dressing behaviour (DB) are included. Publications that did not meet the inclusion criteria but contained relevant information regarding the topic were not included in Table 1 but used in the discussion of the results of the experiments in the next sections.

\section{Publications analyses}

The selected articles are listed in Table 1. The table consists of two categories: (I) thermophysiology and (II) thermal comfort. Described in the table are lighting exposures, the time and the duration of the exposure (as far as known), the number and gender of the subjects that participated in the experiment, and the thermal conditions of the experiments. The effects of the lighting exposure are described for each of the relevant parameters. The results on thermophysiology are described in the section entitled: 'Light and (thermo) physiological responses' and the results on the subjective responses in 'Effects of light on subjective thermal parameters'. 


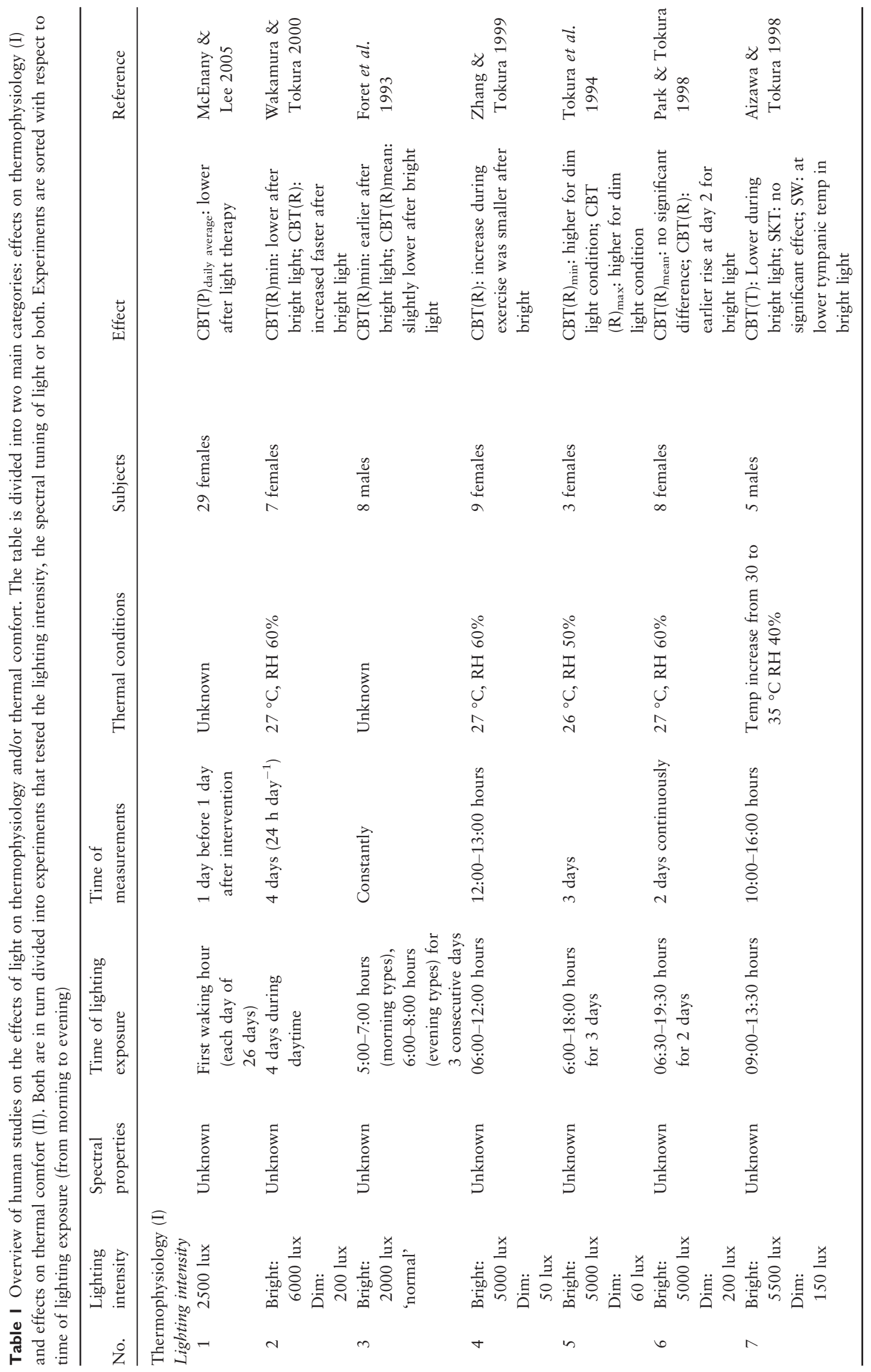




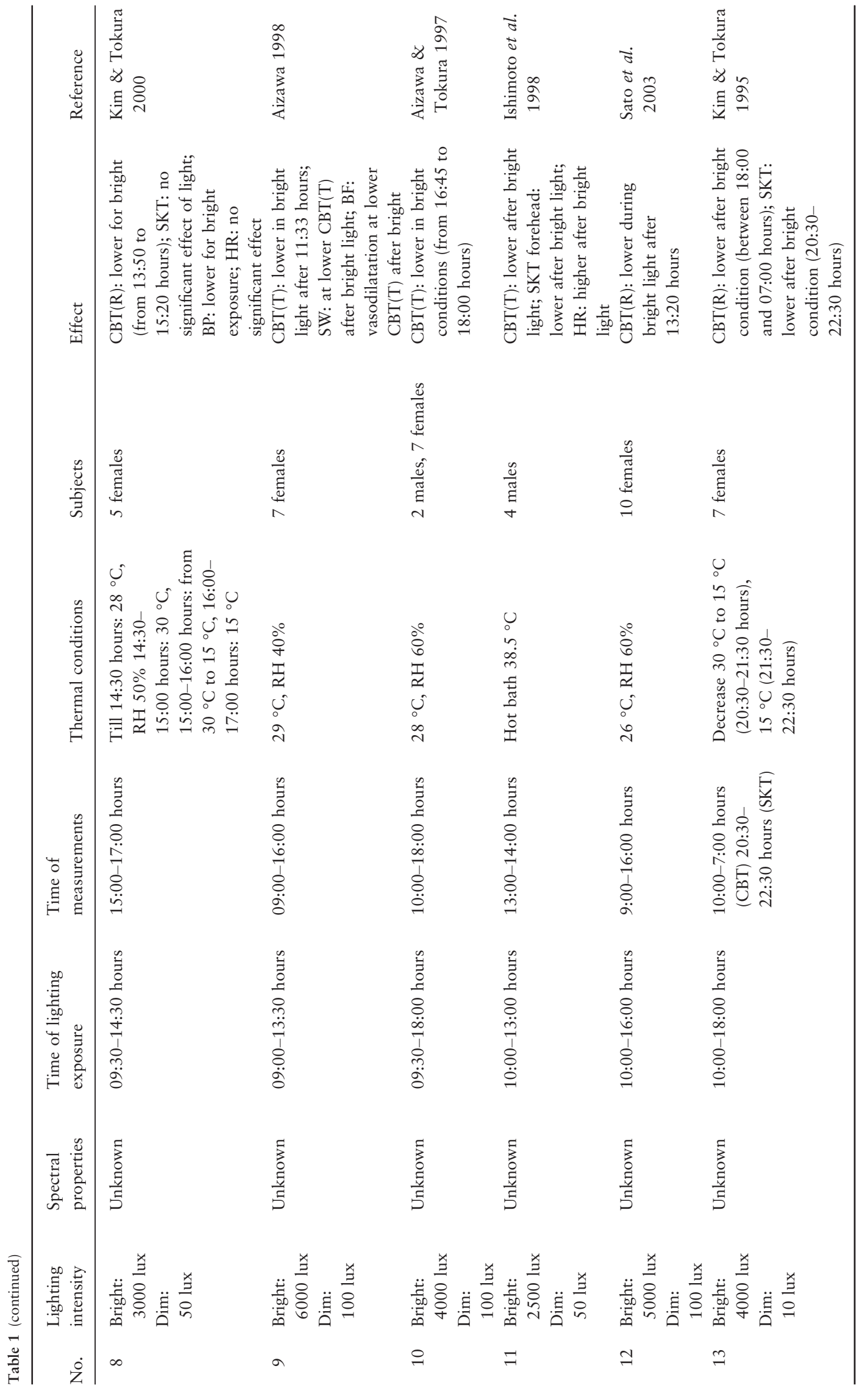




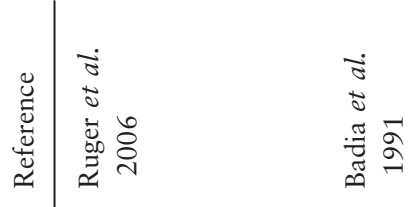

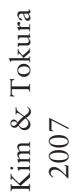

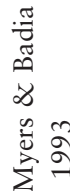

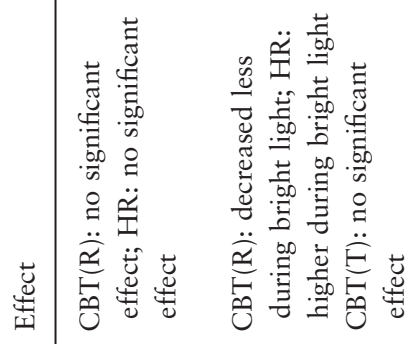

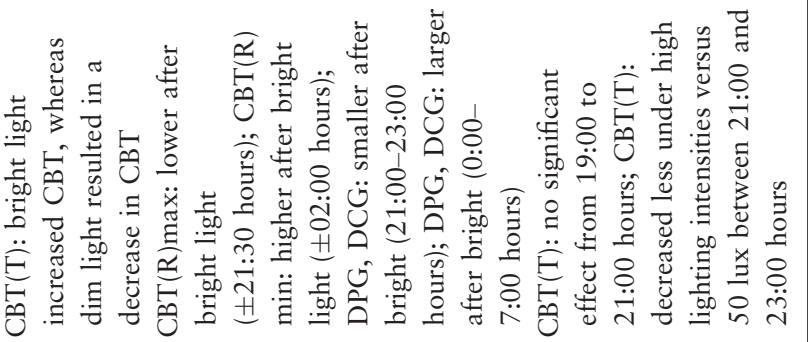

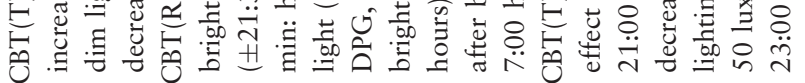
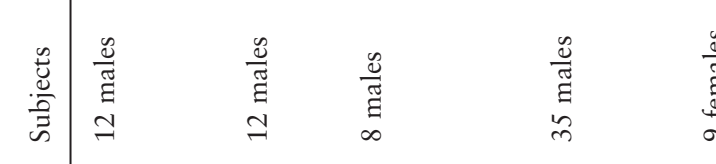

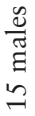

$\begin{array}{lll}0 & & \\ 0 & 0 & 0 \\ 0 & 0 & 0 \\ 0 & i n & 0\end{array}$

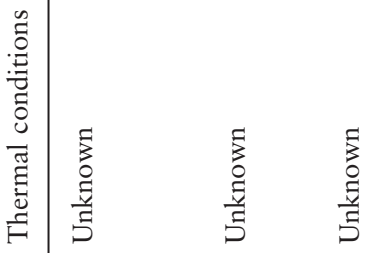<smiles>C1CCC1</smiles>

घ용

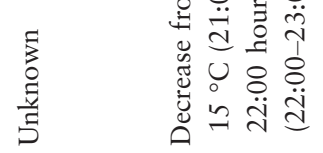

喜

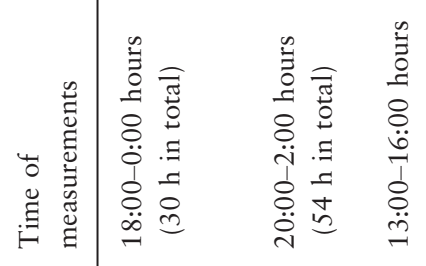

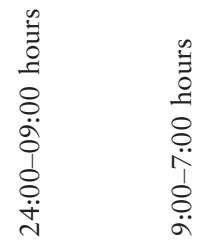

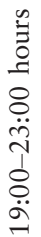

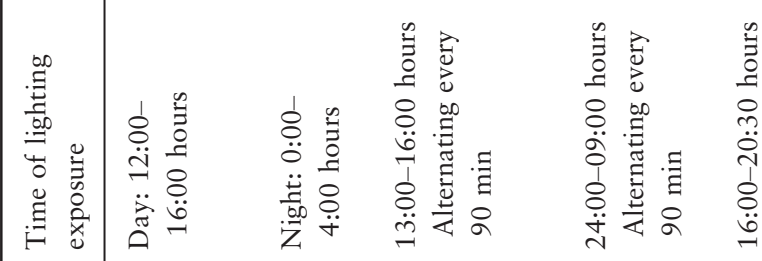

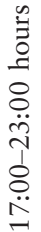

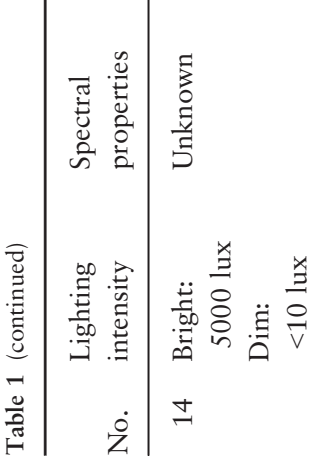

疍

志

5
$\frac{5}{5}$
$\frac{5}{5}$

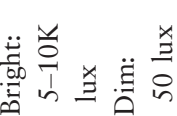

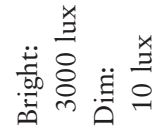

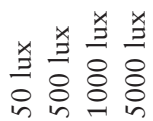

$n$

$\stackrel{6}{2}$

$气$ 


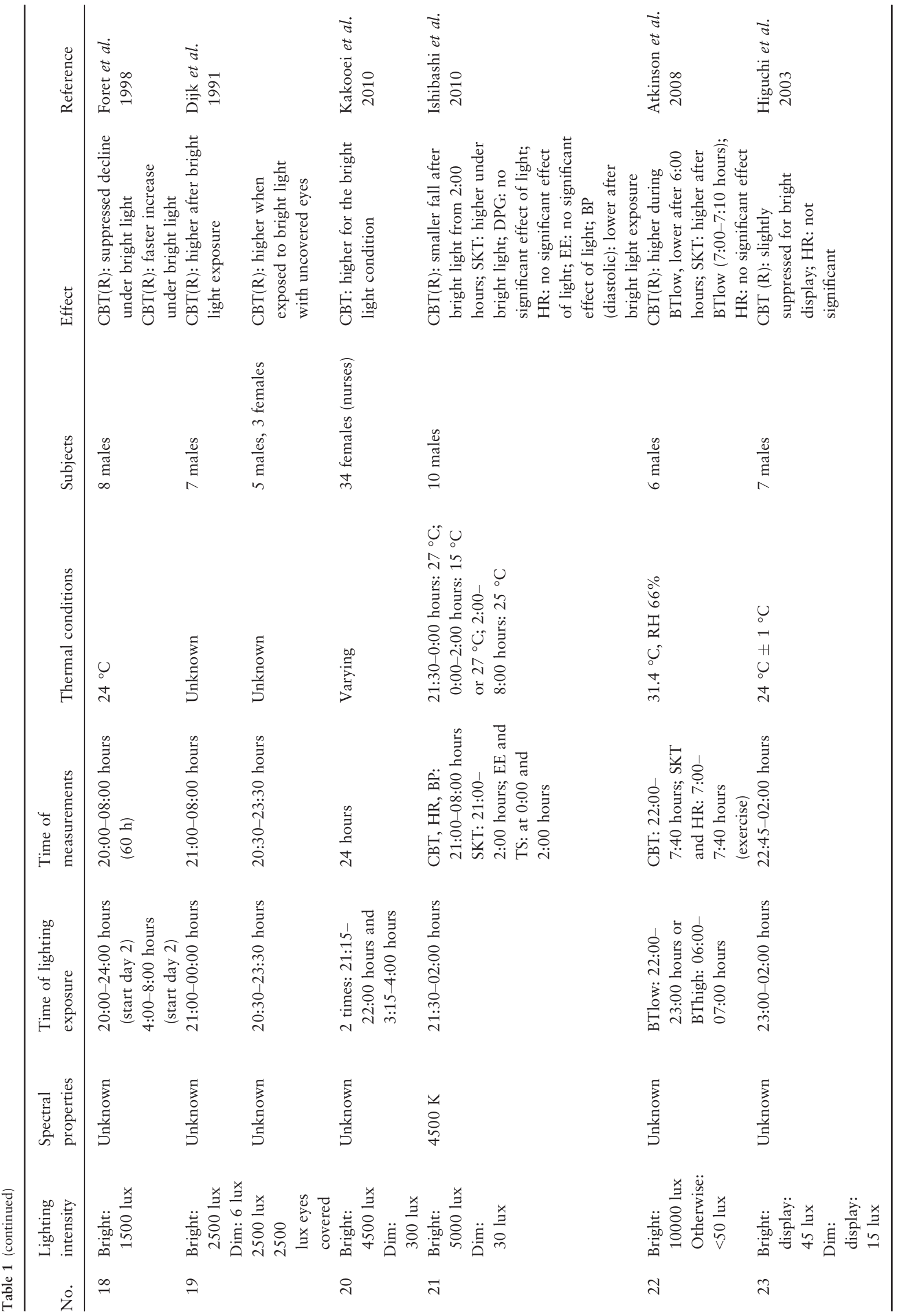




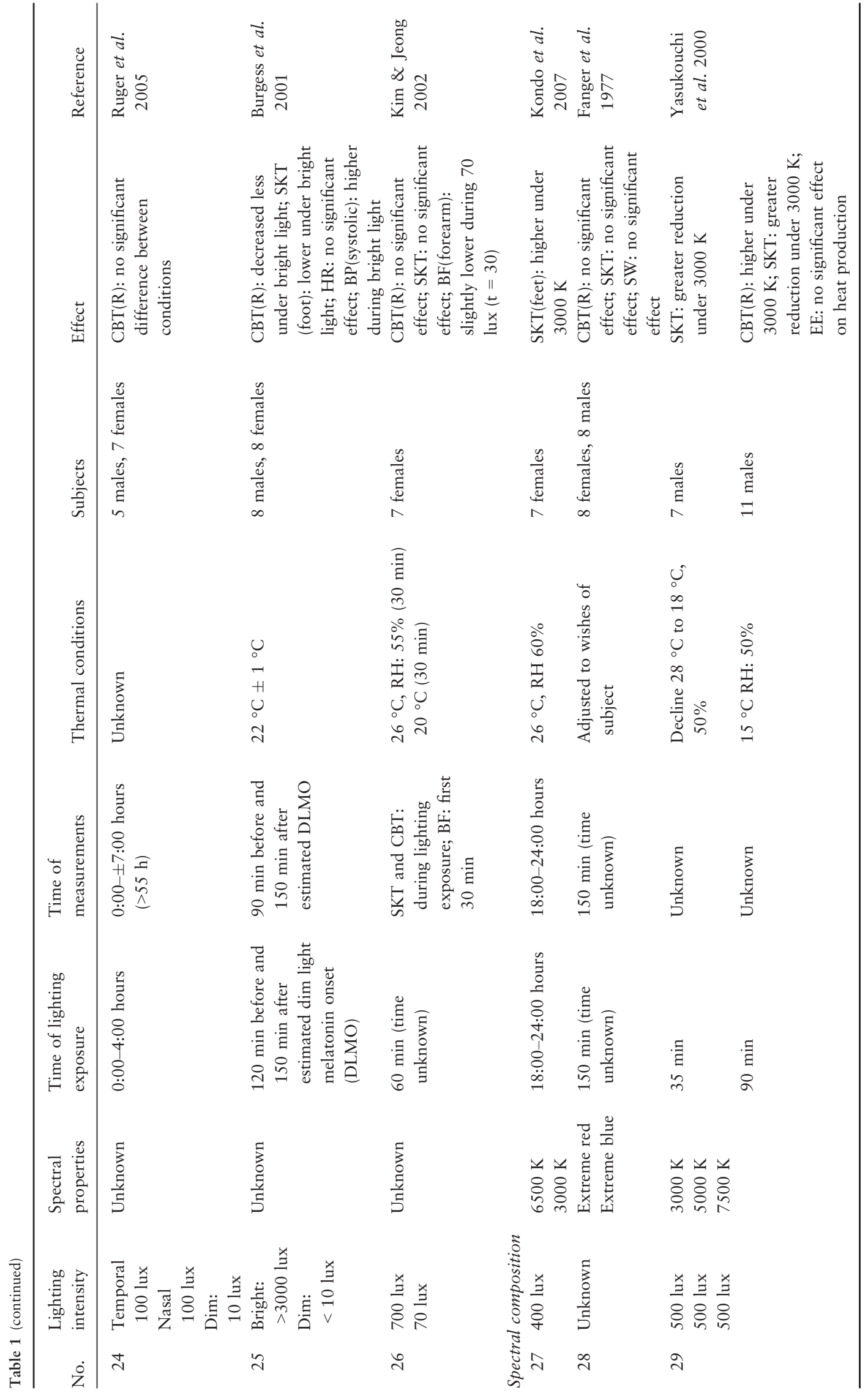




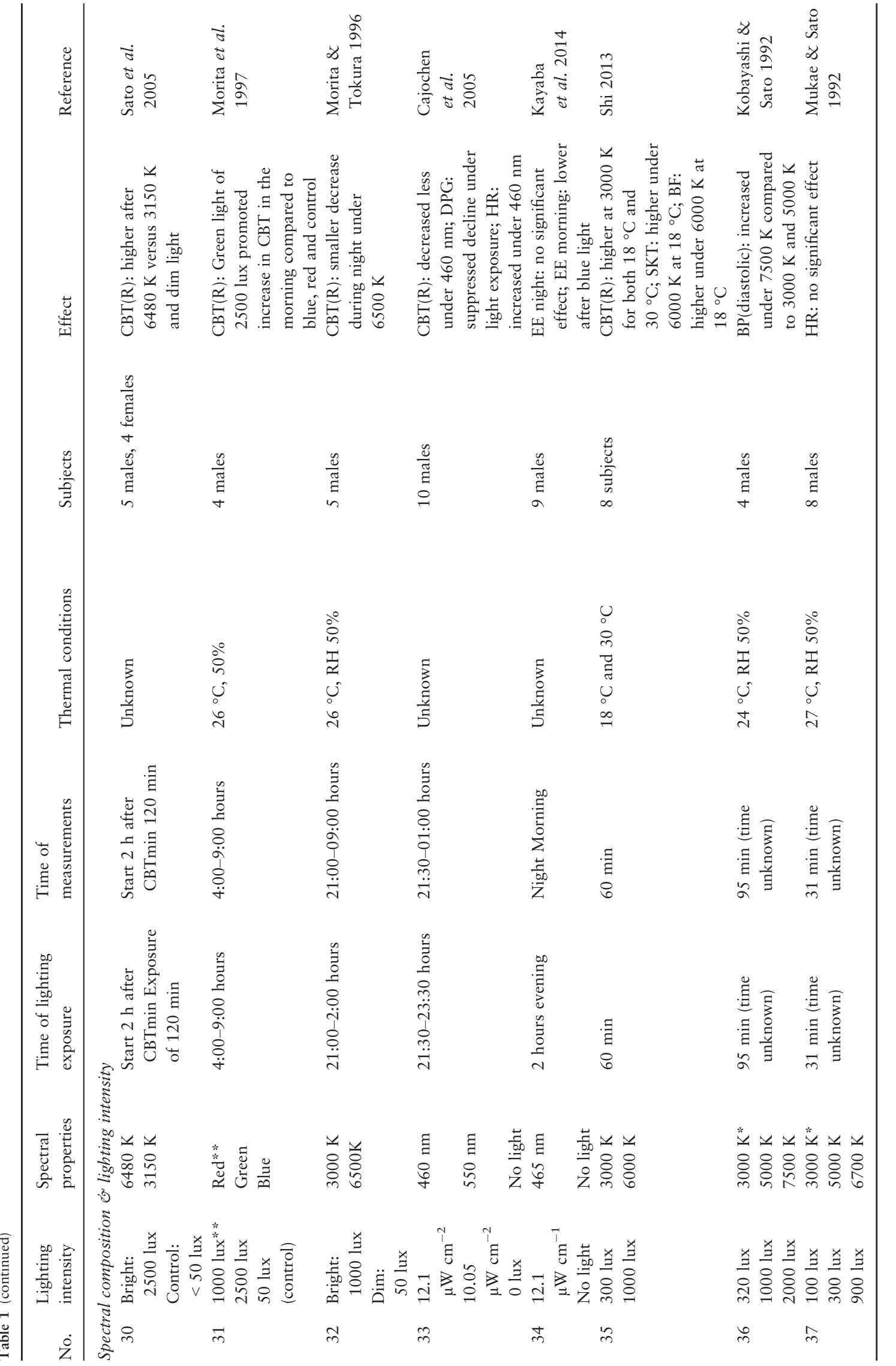




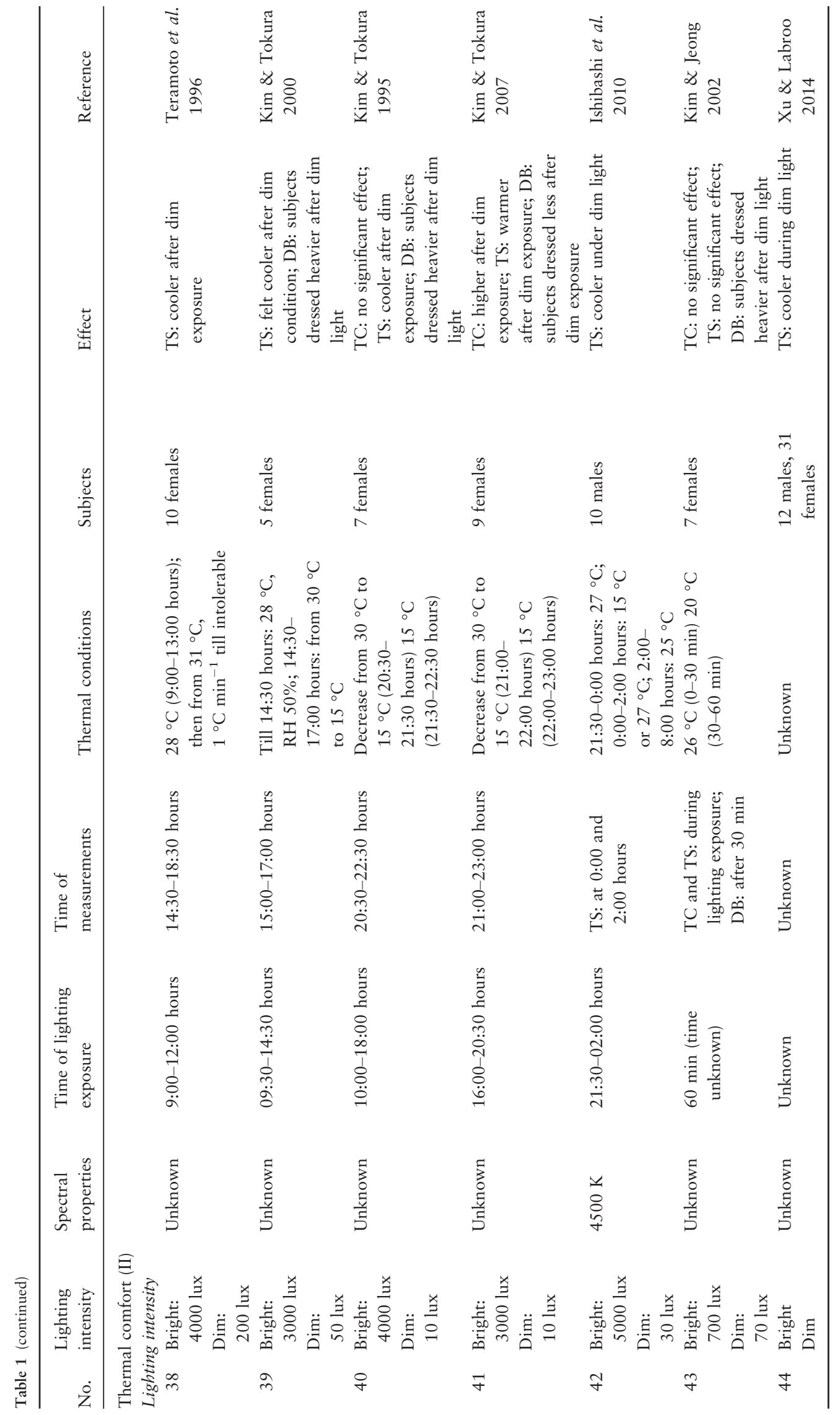




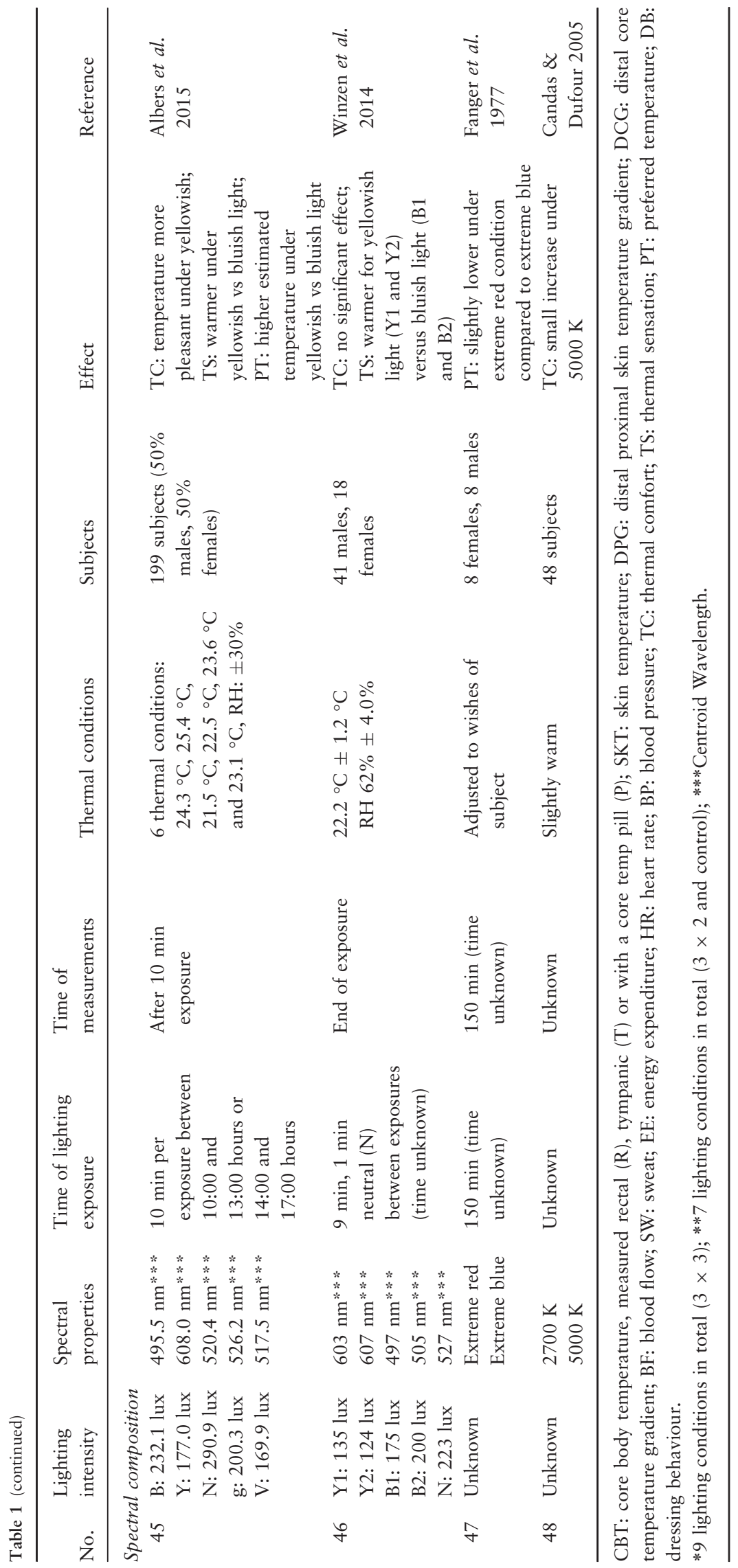




\section{Light and (thermo)physiological responses}

\section{Effect of light on CBT, SKTs and heat loss}

The effect of light in the evening on CBT was tested in experiments \#14-25, 32 and 33 from Table 1. It was found that the decline in CBT in the evening was smaller under bright light (effect between $<0.1^{\circ} \mathrm{C}$ and $0.3^{\circ} \mathrm{C}$ ) as compared to $\operatorname{dim}$ (\#14-23 and 25). Also light that is rich in shorter wavelengths (high CCT) resulted in a smaller decrease, around $0.2^{\circ} \mathrm{C}$, in CBT (\#32 and 33), as compared to light that is rich in longer wavelengths (low CCT). In two of these studies, melatonin was measured and it was found that this smaller decline in CBT went along with a lower concentration of melatonin (\#25 and 33), which is in accordance with the above-described inverse relation of melatonin with CBT (paragraph 3.5). Light that is rich in longer wavelengths (low CCT) was not capable of suppressing the evening decline in CBT (\#32 and \#33). This suggests that the mechanism involved in the light-induced suppression of the natural decline in CBT (in the evening and at night) is influenced by the pRGCs: similar to phase shifting of the circadian rhythm, this effect is most sensitive for shorter wavelengths. When comparing the effects of light during the night on CBT, a 100-lux exposure was not significantly different from a 10-lux exposure (\#24).

Providing bright light in the morning (\#2-4, 7-9 and 10), or morning and afternoon (\#12 and 13), confirms the hypothesis of phase shifting of the circadian rhythm of CBT. Experimental results of these morning bright light exposures show an earlier increase in CBT in the morning (\#2, 3 and 6). Also, a lower CBT of on average $0.1{ }^{\circ} \mathrm{C}$ during the end of the morning (\#7), the afternoon around $0.2{ }^{\circ} \mathrm{C}(\# 4,7-12)$ and evening around $0.1{ }^{\circ} \mathrm{C}(\# 13)$ was found after morning bright light exposure. Two other studies show that the CBT is on average $0.5{ }^{\circ} \mathrm{C}$ lower after bright light $(>2500$ lux) in the morning (\#1 and 5), as compared to light with an intensity of $60 \mathrm{lux}(\# 5)$ or as an addition to everyday light exposure (\#1). Again the inverse relation with melatonin was present (\#7 and 10). Bright light exposure during the afternoon, when melatonin is normally absent, did not result in a change in CBT (\#14, 15).

The different effects of light in the morning, afternoon and evening support the hypothesis that the effects of bright light are based on phase shifting of the circadian rhythm and/or the light-induced suppression of melatonin. However, studies that did not report time of exposure cannot unconditionally be explained by this hypothesis. Experiments performed at an unknown time found that the CCT of light affects CBT: a $0.1{ }^{\circ} \mathrm{C}$ higher CBT was measured under white light that is relatively rich in longer wavelengths $(3000 \mathrm{~K})$ as compared to white light that is relatively rich in shorter wavelengths $[5000 \mathrm{~K}$ and $7500 \mathrm{~K}$ (\#29) and $6000 \mathrm{~K}$ (\#35)]. However, comparing red and blue light did not result in a different CBT (\#28). Moreover, in an experiment that did not report the time of the day, no difference in CBT was found during bright light exposure (700 lux) as compared to exposure to lower light levels (70 lux) (\#26).

Regarding SKTs, it was observed that bright light in the morning and afternoon (as compared to dim light) resulted in an on average $0.5{ }^{\circ} \mathrm{C}$ lower mean SKT in the evening (\#13) and bright light in the morning in an around $0.5{ }^{\circ} \mathrm{C}$ lower forehead SKT in the afternoon (\#11). Other experiments that tested the effects of light in the morning did not find any effect on SKT (\#7 and 8). This absence of an effect on mean SKT does not necessarily implicate that all SKTs were not affected. In the evening, bright light exposure led to an increased mean SKT of $1.0^{\circ} \mathrm{C}(\# 21$ and 22) as compared to light with an intensity $<50$ lux. The SKT of the foot, however, was around $-2.0^{\circ} \mathrm{C}$ lower under bright light exposure in the evening (\#25) as compared to dim light. An explanation could be that bright light in the evening increases proximal SKT and decreases distal SKT. For the DPG, it was found that monochromatic light at both 460 and $550 \mathrm{~nm}$ in the evening suppresses the evening decline of this gradient by $0.7^{\circ} \mathrm{C}$ (\#33). A similar effect on DPG was found during the night after evening bright light exposure as compared to dim light (\#16). Melatonin concentration was also measured and appeared to be lower during the night after bright light (\#16). The suppression of melatonin in the evening resulted in increased proximal temperatures $\left(0.2^{\circ} \mathrm{C}\right)$, decreased distal temperatures $\left(0.5^{\circ} \mathrm{C}\right)$ and a larger DPG (\#16 and 33). Without giving any information about the time of the day and the melatonin levels of subjects, two studies found that SKTs were lower under light with a CCT of $3000 \mathrm{~K}$ compared to $5000 \mathrm{~K}$ and $7500 \mathrm{~K}$ (\#29) and $6000 \mathrm{~K}$ (\#35) while subjects were exposed to cold temperatures. Other experiments that tested the effect of the intensity of light (\#26) and the colour of light (\#28) on SKT, but did not report the time of exposure and did not find any effect on SKT.

The effect of light on SW was studied in three experiments. Comparing the effects of blue light versus red light, no difference in SW was observed (\#28). However, after being exposed to bright light in the morning, the onset of sweating started at $-0.1{ }^{\circ} \mathrm{C}$ lower CBT as compared to dim light (\#7 and 9). As CBT was lower during bright light and there was no significant difference in SKT during both exposures, it 
could be that sweating started at the same time and with the same SKT under both lighting conditions. However, at that time, the CBT was lower under bright light as compared to dim light. Therefore, the results were not conclusive with respect to the effects of light on sweating.

In general, these studies show that bright light in the evening can suppress melatonin and suppress the decrease in CBT and proximal SKT, whereas it decreases distal SKT. Light exposure in the morning results in an earlier increase in CBT along with a more rapid decline in melatonin concentration. Studies carried out during the afternoon did not find any effect of light exposure on CBT and SKT. These findings indicate that the effect of bright light on CBT, DPG and SKT depends on the time of day, the intensity and the spectral composition of the light exposure. However, it is not known whether these effects can occur independent of melatonin suppression or potential phase shifts in the circadian rhythm. Additionally, studies on the effect of lighting exposure on CBT and SKT performed during daytime (office hours) are rare.

\section{Effect of light on heat production}

Physical activity increases human heat production. In cold environments, humans also increase their heat production through shivering and non-shivering thermogenesis (van Ooijen et al. 2007). In warm environments, on the other hand, EE can increase through increased blood circulation, activity of SW glands and increased body temperature (Kingma et al. 2012). Additionally, as described above, heat production also has a circadian rhythm. It is likely that exposure to light is capable of affecting human EE by altering the circadian rhythm. However, we were also interested in the acute effects of light on EE independent of the influence of light on the circadian rhythm. This knowledge could be applied in the design of indoor environments that can help improving the (metabolic) health of building occupants.

Three studies have investigated the effects of light on human EE. EE was not affected by the colour temperature of the light exposure when comparing different CCTs of light, 3000, 5000 and $7500 \mathrm{~K}$ (at an unknown time) (\#29). During the evening, bright light exposure $(\# 21)$ did not result in a different EE as compared to dim light exposure. The third experiment studied blue light exposure in the evening as compared to dim light and found that EE the next morning was significantly lower after the exposure to blue light (\#34). It is plausible to assume that the blue light resulted in a phase delay of the circadian rhythm and therefore caused lower EE the next morning. Another study reported that early morning bright light exposure (>500 lux) was associated with a lower BMI [body mass index: body mass divided by the square of the body height $\left(\mathrm{kg} \mathrm{m}^{-2}\right)$ ] (Reid et al. 2014). Accounting for light levels, activity and food intake of human subjects, one could hypothesize that this result originates from a higher metabolic rate in subjects that were exposed to light levels above 500 lux earlier during the day. However, this still is rather speculative as the study did not correct for possible BMI effects due to the timing of food intake and the duration and quality of sleep. Both studies indicate that a later circadian phase results in a lower EE. The effects of the circadian timing system on EE have also been investigated in mice. Mice that were housed under constant light ( $>180$ lux) had an increased food intake $(+26 \%)$ and decreased EE $(-13 \%)$ as compared to mice housed under a $12-\mathrm{h}$ light and 12-h darkness cycle (Coomans et al. 2013a). In broiler chickens, EE was found to be increased under bright light as compared to dim light, while behaviour was similar (Kim et al. 2014). Whether such effects of light on EE can also occur in man remains to be studied.

\section{Effect of light on cardiovascular parameters}

Table 1 includes four studies measuring the effects of light on BP. Bright light, either in the morning or in the evening, decreases BP (diastolic- $<5 \mathrm{mmHg}$ (\#8 and 21), systolic $-10 \mathrm{mmHg}$ ) as compared to dim light (\#8) and light with an intensity of 300 lux (\#21). However, one study found a higher systolic BP during bright light in comparison with dim light (\#25). Light with a high CCT $(7500 \mathrm{~K})$ also resulted in a $4 \mathrm{mmHg}$ higher diastolic BP as compared to 3000 and $5000 \mathrm{~K}$ light exposure (\#36). The duration and time may be of influence on the effect of intensity and colour. Therefore, no clear conclusions can be drawn from these studies about the effects of light on BP. The effect of light on HR was studied in \#11, 14, 21-23, 25, 33 and 37. One study did not find any effect of light intensity in the morning on $\operatorname{HR}(\# 8)$. A second study observed an increased HR $[+<5$ beats per minute $(\mathrm{bpm})]$ after bright light exposure during the morning as compared to exposure to 50 lux (\#11). Additionally, bright light during the night (5000 lux) was found to be associated with an increase in HR (around $5 \mathrm{bpm}$ higher) (\#14). However, no effect on HR was observed when comparing bright light exposure versus light with a low intensity (<50 lux) during different times of the day and evening (\#14, 21, 22, 23 and 25). Evening exposure to light with a wavelength of $460 \mathrm{~nm}$ increased HR (by $2 \mathrm{bpm}$ ) as compared to exposure to light with a wavelength of 
$550 \mathrm{~nm}$ (\#33). Another study did not find any effect of CCT on HR (\#37). Other visual input, a film of a warm or a cold landscape, was capable of evoking cardiovascular responses. Heart rate was higher while watching a hot landscape compared to a cool landscape, which is according to the authors in line with responses in a real environment (Takakura et al. 2013). No effects on BP were found in that study.

Altogether, it can be concluded that light plays an important role in physiological and thermophysiological responses. The timing of the light exposure is a key factor in the obtained results because light is involved in controlling the circadian rhythm and melatonin secretion. It is not clear whether other psychological mechanisms may also play a role in the interaction between visual information and thermal responses.

\section{Effects of light on subjective thermal parameters}

In this section, we will address the relation between light and thermal behaviour, TS and TC. First, the results of varying lighting intensity will be described followed by the effects of the colour of light.

\section{Effects of lighting intensity on DB, TS and comfort}

Four studies (\#39-41 and 43) focussed on DB after lighting exposures of different intensities. These studies all found an effect of the lighting intensity on the thickness of clothing chosen by the subjects. Two studies found that subjects chose thicker clothing after dim light exposure as compared to bright light exposure (\#39 and 40). However, in the other two studies, subjects chose heavier clothing after bright light exposure in comparison with dim light exposure (\#41 and 43). Three of these studies showed that less heavy clothing went along with a lower CBT (\#39-41). However, in the experiments that were performed during the day, CBT was lower and less heavy clothing was chosen after bright light exposure as compared to dim light. Simultaneously, the experiment in the evening found the same effect on CBT and DB after dim light exposure instead of bright light exposure. This may indicate that less heavy clothing was associated with a lower temperature set point due to the lower CBT. In the fourth study, no difference in CBT was found (\#43).

Experiments also studied the effects of light intensity on TS and TC (\#38-44). TS was evaluated as warmer $(+0.5$ till 1.0 point on the TS scale (ASHRAE, 2004)) during and after being exposed to bright light (>3000 lux) as compared to dim light (\#38-40, 42 and 44), although one experiment found a colder TS
$(-0.5)$ after being exposed to bright light (\#41) and one found no significant effect as compared to dim light exposure (\#43). Comparing the time of exposure and the effect on TS, the results, except from study \#42, may be explained by the change in CBT. Bright light in the morning lowers CBT during the day resulting in a warmer TS. In the evening, bright light suppresses the decline in CBT and this results in a cooler TS. For the experiment that did not find any effect, it could be that the intensity of the bright light condition (700 lux) was too low to obtain an effect. Three studies evaluated TC (\#40, 41 and 43), and only one study measured an effect of the lighting intensity on TC (\#41). In this experiment, subjects were exposed to a cold environment $\left(15^{\circ} \mathrm{C}\right)$ that was either brightly or dimly lit, and TS was colder after bright light. As a consequence, TC was higher after dim light exposure.

It is likely that the effects of light on thermophysiological responses result in altered TS. Indeed, the effects of the intensity of light on DB and TS are found. For DB and TS, it was found that the effect depends on the time of the day and seems to be related to the change in CBT. The time-dependent effects on TS, however, were not consistent. The researches of one study (Xu \& Labroo 2014) report that bright light makes people feel warmer, and it was suggested that these effects arise because more (sun) light is usually associated with the perception of more heat and thus might trigger the hot emotional system (for instance via priming). This can be supported by the notion that emotions can evoke thermal responses (Zhong \& Leonardelli 2008, Ijzerman et al. 2012). However, the role of timing of the lighting exposure and its possible effect on thermophysiology cannot be checked due to the lack of physiological measurements and indication of clock time.

\section{Effect of spectral tuning of light on TS, TC and thermal behaviour}

The effect of colour on TS is sometimes described by the 'hue-heat hypothesis', which states that an environment that is lit by a light spectrum that is rich in frequencies to the red end of the visible spectrum is perceived as warmer as compared to light that is rich in frequencies to the blue end of the visible spectrum (Bennet \& Rey 1972). The experiments \#45-48 all confirmed this hypothesis. Comparing a room with extreme red versus extreme blue light revealed that the PT was slightly lower $\left(0.4^{\circ} \mathrm{C}\right)$ in the red conditions compared to blue (\#47). In a slightly warm room, TC was slightly increased $(+6$ on a scale from 0 to 100) when the room was lit using a CCT of $5000 \mathrm{~K}$ as compared to $2700 \mathrm{~K}(\# 48)$. Moreover, the 
temperature in this room was perceived as somewhat cooler when using the higher CCT, as expected. The effects of the colour of light on TC and TS have also been tested in aircraft simulations. Experiments \#45 and \#46 found that TS was more warm $(+0.1$ till +0.6 (ASHRAE, 2004) TS vote) under white light with a yellow colour tone (rich in longer wavelengths), as compared to white light with a blue colour tone (rich in shorter wavelengths). In one of these studies, TC was also perceived as more pleasant and ambient temperature was estimated to be $0.2{ }^{\circ} \mathrm{C}$ higher under yellow light as compared to blue light (\#45). In the second aircraft simulation study, no significant effect of the light conditions on TC was found (\#46). The hue-heat hypothesis has also been tested the other way around; in cold temperatures, subjects preferred light with low CCTs, while under warm temperatures, high CCTs were preferred (Nakamura \& Oki 2000). Thus, under cold conditions people prefer warm tones of white and yellowish colours, while under warm conditions people prefer cold tones of light and bluish colours.

It must be noted that the results obtained with coloured objects and environments cannot be directly translated into coloured lighting conditions. Already in 1926, Mogensen and English tested the effect of colour of an object on TS in an experiment where subjects had to estimate which of two cylinders felt warmer; each cylinder was covered with a different saturated colour, while the temperature of both cylinders was equal $\left(42^{\circ} \mathrm{C}\right)$. The colours green and blue were rated most often as being most warm, and red and purple were perceived as least warm (Mogensen \& English 1926). Although the differences were small, these results were in contrast to what was expected as purple and red are known to be experienced as 'warm' colours. The researchers state that the warmth of colours is insufficient to modify the judgment of tactual warmth. However, it could also be that the expectation of a warmer object (with a warm colour) resulted in a lower estimation of the actual temperature. The effects of red and blue were also tested using red and blue carpet and curtains. Experiments under an increasing and a decreasing room temperature have been conducted. For an increasing temperature, the measured effects confirm the hue-heat hypothesis; the red interior resulted is a warmer TS. However, for the decreasing temperature, the opposite was found and subjects felt cooler when surrounded by the red interior (Kuno et al. 1986).

Although the differences are small, the studies that used light to create different CCTs within a room do confirm that the thermal environment is perceived as warmer under yellow or reddish light (\#45-48). The visual appearance of the environment may thus influ- ence the subjective assessment of the thermal environment. This was supported by a study that asked subjects to rate their thermal environment while watching a film of a cool or a warm landscape (icebergs versus desert). TS was higher when watching a warm landscape (Takakura et al. 2013). Again it is not possible to conclude that the effects caused by light are obtained only via the visual pathway, because physiological parameters and clock time of the experiments were not provided. Only experiment \#47 also measured CBT, SKT and SW. This experiment found no effect of light on these parameters, while a slightly higher PT under blue light was measured.

\section{Interaction between indoor environmental parameters}

Several studies suggest that the interaction between light and TC may be due to the overall appreciation of the indoor environment; for example, if one of the environmental parameters is rated positive, it also improves the other indoor parameters. Excellent lighting conditions may compensate for a poor thermal environment or acoustics (Humphreys 2005). However, an experiment that evaluated the effects of thermal conditions on visual comfort appraisal found no interaction (Laurentin et al. 2000). Still, it was found that a higher CCT (as compared to a lower CCT) was associated with a cooler perception of air temperature, which is in line with the hue-heat hypothesis (Laurentin et al. 2000).

In conclusion, studies have shown that lighting exposure can alter TS and TC. Different mechanisms can explain how these effects are obtained. The effect of light on thermophysiology could lead to an altered TS, but also the visual impression of a warmer environment could affect TS. Additionally, the interaction of different indoor environmental parameters, such as temperature, light and acoustics, could affect each other. Still, how these three parameters interact has not yet been described. The absence of time information (regarding both the internal subjective time and external time) of the light exposures and the lack of physiological measurements make it almost impossible to verify how these different parameters may interact, and more research into this field is needed.

\section{Discussion}

\section{Light, thermophysiology and TC}

Light is capable of evoking physiological responses that are not directly linked to visual light perception, an example being thermoregulation. Figure 5, which is a simplification of Figure 3, shows the possible 
Figure 5 Effects of light on thermal sensation and comfort, thermal behaviour and thermophysiology. The solid lines denote relations that have been established. The dashed lines indicate probable, not yet established, relations.

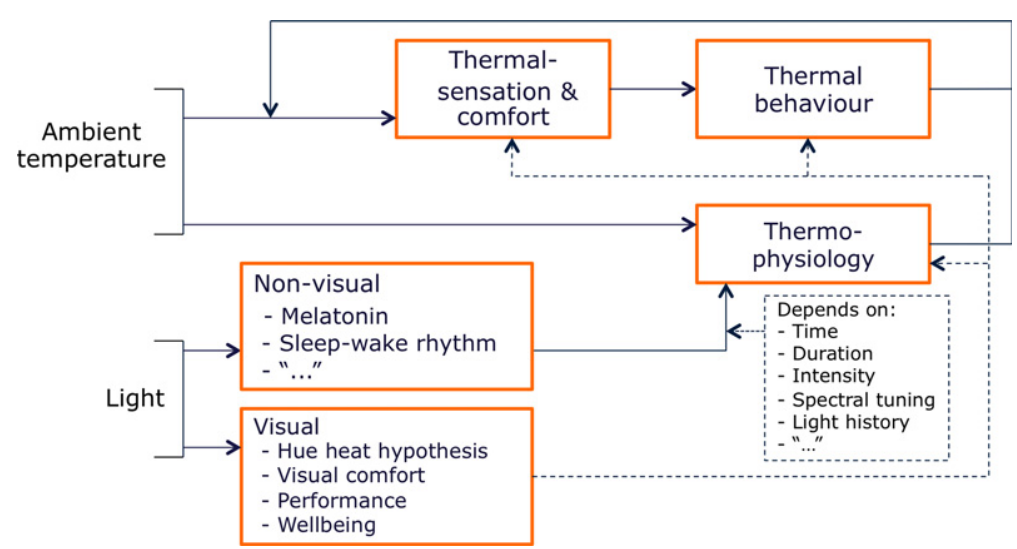

relations between lighting intensity, lighting colour and thermoregulation.

The literature survey revealed that a limited set of human experiments confirm the link between light and thermophysiology, TC, TS and thermal behaviour. The non-visual effects of light depend on the (circadian) timing of the light exposure. Studies also explain the thermal responses by perception of the visual environment affecting thermophysiology and TC. This psychological effect is based on the link between the colour (tone) and the intensity of light and how these aspects are associated with heat or cold. Because most studies that investigated this association did not perform physiological measurements and many did not report the (internal and/or external) timing of the experiments, the effect is not completely understood. To check for the effects of circadian timing, well-controlled studies are required.

Figure 5 illustrates current knowledge of the interaction of light and thermal responses. The relation between visual information and, on the other hand, thermophysiology, TS, TC and thermal behaviour is indicated with dashed lines, as this interaction is not yet clearly understood. Studies that used experimental light conditions to influence thermophysiology revealed that there is a relation between light and thermophysiology via the non-visual pathway. It appeared that the intensity and colour of light and the time and duration of the light exposure influence the obtained effects. Whether light also has a direct influence on thermophysiology, without influencing melatonin or the circadian rhythm, remains to be elucidated. Future research should focus on the relations and influencing factors indicated with the dashed lines in Figure 5.

\section{Spectral tuning of light and intensities}

The timing and duration of the lighting exposure, as well as the intensity and spectral tuning of light, can affect thermophysiology. Contradicting results were obtained for the physiological responses, when applying the same light exposure in the morning and evening. The illuminance threshold, above which the effects can be obtained, and the optimal wavelengths or colour spectrum of the lighting exposure are not fully known yet. Light with a peak intensity around $480 \mathrm{~nm}$, the peak sensitivity of the pRGCs, seems to be a powerful stimulus for suppressing melatonin and also powerfully affects other physiological processes. Surprisingly, for alertness and performance, it was found that daytime red light exposure, when preceded by $10 \mathrm{~min}$ of dim light exposure, yields a higher alertness and performance as compared to white light exposure (Sahin et al. 2014). Prior light history and the intensity chosen for the light exposure could be a contributing factor to this outcome. No single spectral efficiency function accounts for responses under all conditions. Findings indicate that rods, cones and pRGCs all can contribute to non-image-forming responses (Lucas et al. 2014).

In some studies, temperature was judged as being cooler under blue-rich light as compared to red light, or when viewing a cold landscape as compared to viewing a warm landscape. However, most studies tested only short-term effects, with an experimental time of approx. 10-15 min. It remains unknown whether the effects also exist after a longer exposure duration. Additionally, well-controlled timing of experiments that include physiological measurements is necessary to investigate thermal responses to light and to explore whether these responses are mediated via visual and/or non-visual pathways. Moreover, further research is needed to establish whether the effects of light on TS and TC are of practical significance.

It is clear that light affects thermophysiological responses, but more research is necessary about how the conditions and the different parameters interact and influence human thermal responses. To get a 
better understanding, a more consistent control and description of both the thermal and the visual conditions of experiments is required. Responses may be different in a warm or cold environment, and as the sensitivity of the photoreceptor cells differs, the intensity as well as the spectral tuning of the light exposure should be reported. Also the timing of the light exposure with respect to time of day and the internal time (circadian phase), and the duration of the exposure are important factors to consider.

\section{Applications}

Knowledge of the interaction between light, thermophysiology and TC should be applied in human physiological experimental research, as the interaction could be an important confounding factor. Further understanding about the relation between light, TC and thermophysiology could lead to improvements in the design of the indoor environment. Dynamic lighting adjusted to season, time of the day and daylight could be required. When light can contribute to an improved TC, this may enable for energy savings within heating, ventilation and air-conditioning systems.

\section{Acknowledgements}

This project was funded by the STW-Philips Electronics Nederland B.V. Partnership Program 'Advanced Sustainable Lighting Solutions' (no. 12733).

\section{Conflict of interest}

Luc JM Schlangen is an employee of Royal Philips Electronics N.V., the Netherlands.

\section{References}

Aizawa, S. 1998. Influence of bright light exposure for several hours during the daytime on cutaneous vasodilation and local sweating induced by an exercise heat load. Eur J Appl Physiol 78, 303-307.

Aizawa, S. \& Tokura, H. 1997. Exposure to bright light for several hours during the daytime lowers tympanic temperature. Int J Biometeorol 41, 90-93.

Aizawa, S. \& Tokura, H. 1998. The Influence of Bright Light Exposure for several hours during daytime on tympanic temperature level at sweating onset. J Therm Biol 23, 99-106.

Albers, F., Maier, J. \& Marggraf-Micheel, C. 2015. In search of evidence for the hue-heat hypothesis in the aircraft cabin. Lighting Res Technol 47, 483-494.

Arendt, J. \& Skene, D.J. 2005. Melatonin as a chronobiotic. Sleep Med Rev 9, 25-39.

Aschoff, J. 1983. Circadian control of body temperature. J Therm Biol 8, 143-147.
ASHRAE. 2004. Standard-55, Thermal Environment Conditions for Human Occupancy. American Society of Heating, Refrigerating and Air-Conditioning Engineering, Atlanta, GA.

Atkinson, G., Barr, D., Chester, N., Drust, B., Gregson, W., Reilly, T. \& Waterhouse, J. 2008. Bright light and thermoregulatory responses to exercise. Int J Sports Med 29, 188-193.

Badia, P., Myers, B., Boecker, M., Culpepper, J. \& Harsh, J.R. 1991. Bright light effects on body temperature, alertness, EEG and behavior. Physiol Behav 50, 583-588.

Bellia, L. \& Bisegna, F. 2013. From radiometry to circadian photometry: a theoretical approach. Build Environ 62, 6368.

Bellia, L., Bisegna, F. \& Spada, G. 2011. Lighting in indoor environments: visual and non-visual effects of light sources with different spectral power distributions. Build Environ 46, 1984-1992.

Bennet, C.A. \& Rey, P. 1972. What's so hot about red. Hum Factors 14, 149-154.

Berson, D.M. 2003. Strange vision: ganglion cells as circadian photoreceptors. Trends Neurosci 26, 314-320.

Berson, D.M., Dunn, F.A. \& Takao, M. 2002. Phototransduction by retinal ganglion cells that set the circadian clock. Science 295, 1070-1073.

van Bommel, W.J. 2006. Non-visual biological effect of lighting and the practical meaning for lighting for work. Appl Ergon 37, 461-466.

van Bommel, W.J.M. \& van den Beld, G.J. 2004. Lighting for work: a review of visual and biological effects. Lighting Res Technol 36, 255-269.

Boyce, P.R. 2003. Human Factors in Lighting, 2nd edn. Lighting Research Center, London.

Brainard, G.C., Hanifin, J.P., Greeson, J.M., Byrne, B., Glickman, G., Gerner, E. \& Rollag, M.D. 2001. Action spectrum for melatonin regulation in humans: evidence for a novel circadian photoreceptor. J Neurosci 21, 6405-6412.

Burgess, H.J., Sletten, T., Savic, N., Gilbert, S.S. \& Dawson, D. 2001. Effects of bright light and melatonin on sleep propensity, temperature, and cardiac activity at night. J Appl Physiol (1985) 91, 1214-1222.

Cajochen, C. 2007. Alerting effects of light. Sleep Med Rev 11, 453-464.

Cajochen, C., Khalsa, S.B., Wyatt, J.K., Czeisler, C. \& Dijk, D.J. 1999. EEG and ocular correlates of circadian melatonin phase and human performance decrements during sleep loss. Am J Physiol 277, R640-R649.

Cajochen, C., Krauchi, K. \& Wirz-Justice, A. 2003. Role of melatonin in the regulation of human circadian rhythms and sleep. J Neuroendocrinol 15, 532-537.

Cajochen, C., Munch, M., Kobialka, S., Krauchi, K., Steiner, R., Oelhafen, P., Orgul, S. \& Wirz-Justice, A. 2005. High sensitivity of human melatonin, alertness, thermoregulation, and heart rate to short wavelength light. J Clin Endocrinol Metab 90, 1311-1316.

Candas, V. \& Dufour, A. 2005. Thermal comfort: multisensory interactions? J Physiol Anthropol Appl Human Sci 24, 33-36.

Cardinali, D.P. \& Pevet, P. 1998. Basic aspects of melatonin action. Sleep Med Rev 2, 175-190. 
Carlucci, S., Causone, F., De Rosa, F. \& Pagliano, L. 2015. A review of indices for assessing visual comfort with a view to their use in optimization processes to support building integrated design. Renew Sustain Energy Rev 47, 1016-1033.

Chang, A.M., Scheer, F.A. \& Czeisler, C.A. 2011. The human circadian system adapts to prior photic history. J Physiol 589, 1095-1102.

Chang, A.M., Santhi, N., St Hilaire, M., Gronfier, C., Bradstreet, D.S., Duffy, J.F., Lockley, S.W., Kronauer, R.E. \& Czeisler, C.A. 2012. Human responses to bright light of different durations. J Physiol 590, 3103-3112.

Cipolla-Neto, J., Amaral, F.G., Afeche, S.C., Tan, D.X. \& Reiter, R.J. 2014. Melatonin, energy metabolism and obesity: a review. J Pineal Res 56, 371-381.

Coomans, C.P., van den Berg, S.A.A., Houben, T., van Klinken, J.B., van den Berg, R., Pronk, A.C.M., Havekes, L.M., Romijn, J.A., van Dijk, K.W., Biermasz, N.R. \& Meijer, J.H. 2013a. Detrimental effects of constant light exposure and high-fat diet on circadian energy metabolism and insulin sensitivity. FASEB J 27, 1721-1732.

Coomans, C.P., van den Berg, S.A.A., Lucassen, E.A., Houben, T., Pronk, A.C.M., van der Spek, R.D., Kalsbeek, A., Biermasz, N.R., Willems van Dijk, K., Romijn, J.A. \& Meijer, J.H. 2013b. The suprachiasmatic nucleus controls circadian energy metabolism and hepatic insulin sensitivity. Diabetes 62, 1102-1108.

Craig, A.D., Chen, K., Bandy, D. \& Reiman, E.M. 2000. Thermosensory activation of insular cortex. Nat Neurosci 3, 184-190.

Deacon, S., English, J. \& Arendt, J. 1994. Acute phase-shifting effects of melatonin associated with suppression of core body temperature in humans. Neurosci Lett 178, 32-34.

Deurveilher, S., Burns, J. \& Semba, K. 2002. Indirect projections from the suprachiasmatic nucleus to the ventrolateral preoptic nucleus: a dual tract-tracing study in rat. Eur J Neurosci 16, 1195-1213.

Dijk, D.J., Cajochen, C. \& Borbely, A.A. 1991. Effect of a single 3-hour exposure to bright light on core body temperature and sleep in humans. Neurosci Lett 121, 5962.

Dijk, D.J., Boulos, Z., Eastman, C.I., Lewy, A.J., Campbell, S.S. \& Terman, M. 1995. Light treatment for sleep disorders: consensus report. II. Basic properties of circadian physiology and sleep regulation. J Biol Rhythms 10, 113-125.

Dijk, D.J., Shanahan, T.L., Duffy, J.F., Ronda, J.M. \& Czeisler, C. 1997. Variation of electroencephalographic activity during non-rapid eye movement and rapid eye movement sleep with phase of circadian melatonin rhythm in humans. J Physiol 505.3, 851-858.

Dimicco, J.A. \& Zaretsky, D.V. 2007. The dorsomedial hypothalamus: a new player in thermoregulation. Am J Physiol Regul Integr Comp Physiol 292, R47-R63.

Donald, I.A.N. \& Siu, O.-L. 2001. Moderating the stress impact of environmental conditions: the effect of organizational commitment in Hong Kong and China. J Environ Psychol 21, 353-368.

Falchi, F., Cinzano, P., Elvidge, C.D., Keith, D.M. \& Haim, A. 2011. Limiting the impact of light pollution on human health, environment and stellar visibility. J Environ Manage 92, 2714-2722.

Fanger, P.O., Breum, N.O. \& Jerking, E. 1977. Can colour and noise influence man's thermal comfort? Ergonomics 20, 11-18.

Foret, J., Aguirre, A., Touitou, Y., Clodore, M. \& Benoit, O. 1993. Effect of morning bright light on body temperature, plasma cortisol and wrist motility measured during 24 hour of constant conditions. Neurosci Lett 155, 155-158.

Foret, J., Daurat, A. \& Tirilly, G. 1998. Effect of bright light at night on core temperature, subjective alertness and performance as a function of exposure time. Scand J Work Environ Health 24, 115-120.

Gilbert, S.S., van den Heuvel, J. \& Dawson, D. 1999. Daytime melatonin and temazepam in young adult humans: equivalent effects on sleep latency and body temperatures. J Physiol 514, 905-914.

Gonnissen, H.K.J. 2013. The Broken Cycle of Sleep, Energy Balance through Circadian Alignment. University of Maastricht, Maastricht.

Hatori, M. \& Panda, S. 2010. The emerging roles of melanopsin in behavioral adaptation to light. Trends Mol Med $16,435-446$.

van der Helm-van Mil, A.H., van Someren, E.J., van den Boom, R., van Buchem, M.A., de Craen, A.J. \& Blauw, G.J. 2003. No influence of melatonin on cerebral blood flow in humans. J Clin Endocrinol Metab 88, 5989-5994.

Higuchi, S., Motohashi, Y., Liu, Y., Ahara, M. \& Kaneko, Y. 2003. Effects of VDT tasks with a bright display at night on melatonin, core temperature, heart rate, and sleepiness. J Appl Physiol (1985) 94, 1773-1776.

Huber, R., de Boer, T., Schwierin, B. \& Tobler, I. 1998. Effect of melatonin on sleep and brain temperature in the Djungarian hamster and the rat. Physiol Behav 65, 77-82.

Humphreys, M.A. 2005. Quantifying occupant comfort: are combined indices of the indoor environment practicable? Build Res Inf 33, 317-325.

Ijzerman, H., Gallucci, M., Pouw, W.T., Weibetagerber, S.C., Van Doesum, N.J. \& Williams, K.D. 2012. Coldblooded loneliness: social exclusion leads to lower skin temperatures. Acta Psychol (Amst) 140, 283-288.

Ishibashi, K., Arikura, S., Kozaki, T., Higuchi, S. \& Yasukouchi, A. 2010. Thermoregulatory effect in humans of suppressed endogenous melatonin by pre-sleep bright-light exposure in a cold environment. Chronobiol Int 27, 782-806.

Ishimoto, A., Kim, H.E., Rutkowska, D., Tanaka, S. \& Tokura, H. 1998. Physiological significance of 3-h bright and dim light exposure prior to taking a bath for core and forehead skin temperatures and heart rate during 1-h bathing of $38.5^{\circ} \mathrm{C}$. J Therm Biol 23, 353-357.

Jagannath, A., Peirson, S.N. \& Foster, R.G. 2013. Sleep and circadian rhythm disruption in neuropsychiatric illness. Curr Opin Neurobiol 23, 888-894.

Kakooei, H., Arakani, Z.Z., Ayattollahi, M.T., Karimian, M., Saraji, G.N. \& Owji, A.A. 2010. The effect of bright light on physiological circadian rhythms and subjective alertness of shift work nurses in Iran. Int J Occup Saf Ergon 16, 477-485.

Kayaba, M., Iwayama, K., Ogata, H., Seya, Y., Kiyono, K., Satoh, M. \& Tokuyama, K. 2014. The effect of nocturnal 
blue light exposure from light-emitting diodes on wakefulness and energy metabolism the following morning. Environ Health Prev Med 19, 354-356.

Kim, S.H. \& Jeong, W.S. 2002. Influence of illumination on autonomic thermoregulation and choice of clothing. Int J Biometeorol 46, 141-144.

Kim, H.E. \& Tokura, H. 1995. Influence of different light intensities during the daytime on evening dressing behavior in the cold. Physiol Behav 58, 779-783.

Kim, H.E. \& Tokura, H. 2000. Influence of light intensities on dressing behavior in elderly people. J Physiol Anthropol Appl Human Sci 19, 13-19.

Kim, H.E. \& Tokura, H. 2007. Influence of two different light intensities from 16:00 to 20:30 hours on evening dressing behavior in the cold. Coll Antropol 31, 145-151.

Kim, C., Lee, S.R. \& Lee, S.J. 2014. Effects of light color on energy expenditure and behavior in broiler. Asian-Australas J Anim Sci 27, 1044-1049.

Kingma, B.R., Frijns, A.J. \& van Marken Lichtenbelt, W.D. 2012. The thermoneutral zone: implications for metabolic studies. Front Biosci E4, 1975-1985.

Knez, I. 1995. Effects of indoor lighting on mood and cognition. J Environ Psychol 15, 39-51.

Kobayashi, H. \& Sato, M. 1992. Physiological responses to illuminance and color temperature of lighting. Ann Physiol Anthropol 11, 45-49.

Kondo, M., Kanikowska, D. \& Tokura, H. 2007. Influence of different wavelengths of evening indoor lighting on salivary secretion and cutaneous temperature of the feet. Coll Antropol 31, 969-972.

Krauchi, K. \& Wirz-Justice, A. 1994. Circadian rhythm of heat production, heart rate, and skin and core temperature under unmasking conditions in men. Am J Physiol 267, R819-R829.

Krauchi, K., Cajochen, C., Werth, E. \& Wirz-Justice, A. 1999. Warm feet promote the rapid onset of sleep. Nature 401, 36-37.

Krauchi, K., Cajochen, C., Werth, E. \& Wirz-Justice, A. 2000. Functional link between distal vasodilation and sleep onset latency? Am J Physiol Regul Integr Comp Physiol 278, R741-R748.

Krauchi, K., Cajochen, C., Pache, M., Flammer, J. \& WirzJustice, A. 2006. Thermoregulatory effects of melatonin in relation to sleepiness. Chronobiol Int 23, 475-484.

Küller, R. \& Wetterberg, L. 1993. Melatonin, cortisol, EEG, ECG and subjective comfort in healthy humans: impact of two fluorescent lamp types at two light intensities. Lighting Res Technol 25, 71-80.

Kuno, S., Ohno, H. \& Nakahara, N. 1986. Thermal sensation in transitional conditions and the hue-heat hypothesis. In: Environments in Transition. IAPS 9th International Conference, Haifa, Israel, 7-10 July 1986.

Lack, L.C., Gradisar, M., Van Someren, E.J., Wright, H.R. \& Lushington, K. 2008. The relationship between insomnia and body temperatures. Sleep Med Rev 12, 307-317.

Laurentin, C., Bermtto, V. \& Fontoynont, M. 2000. Effect of thermal conditions and light source type on visual comfort appraisal. Lighting Res Technol 32, 223-233.
LeGates, T.A., Fernandez, D.C. \& Hattar, S. 2014. Light as a central modulator of circadian rhythms, sleep and affect. Nat Rev Neurosci 15, 443-454.

Leglise, A. 2008. Progress in Circadian Rhythm Research. Nova Biomedical Books, New York, NY.

Lucas, R.J., Peirson, S.N., Berson, D.M., Brown, T.M., Cooper, H.M., Czeisler, C.A., Figueiro, M.G., Gamlin, P.D., Lockley, S.W., O’Hagan, J.B., Price, L.L., Provencio, I., Skene, D.J. \& Brainard, G.C. 2014. Measuring and using light in the melanopsin age. Trends Neurosci 37, 19.

Manav, B. 2007. An experimental study on the appraisal of the visual environment at offices in relation to colour temperature and illuminance. Build Environ 42, 979-983.

van Marken Lichtenbelt, W.D., Vanhommerig, J.W., Smulders, N.M., Drossaerts, M.A.F.L., Kemerink, G.J., Bouvy, N.D., Schrauwen, P. \& Teule, G.J. 2009. Cold-activated brown adipose tissue in healthy men. $N$ Engl J Med 360, 1500-1508.

Martin, J.H. 2003. The hypothalamus and regulation of endocrine and visceral functions. In: Neuroanatomy: text and atlas, 3rd edn, pp. 351-376. McGraw-Hill, New York, NY.

Mather, G. 2009. Foundations of Sensation and Perception, 2nd revised edn. Taylor \& Francis Ltd, New York, NY.

McEnany, G.W. \& Lee, K.A. 2005. Effects of light therapy on sleep, mood, and temperature in women with nonseasonal major depression. Issues Ment Health Nurs 26, 781794.

Mogensen, M.F. \& English, H.B. 1926. The apparent warmth of colors. Am J Physiol 37, 427-428.

Morita, T. \& Tokura, H. 1996. Effects of lights of different color temperature on the nocturnal changes in core temperature and melatonin in humans. J Physiol Anthropol $15,243-246$.

Morita, T., Tokura, H., Wakamura, T., Park, S.J. \& Teramoto, Y. 1997. Effects of the morning irradiation of light with different wavelengths on the behavior of core temperature and melatonin in humans. J Physiol Anthropol Appl Human Sci 16, 103-105.

Morrison, S.F. \& Nakamura, K. 2011. Central neural pathways for thermoregulation. Front Biosci 16, 74-104.

Mukae, H. \& Sato, M. 1992. The effect of color temperature of lighting sources on the autonomic nervous functions. Ann Physiol Anthropol 11, 533-538.

Myers, B.L. \& Badia, P. 1993. Immediate effects of different light intensities on body temperature and alertness. Physiol Behav 54, 199-202.

Nakamura, H. \& Oki, M. 2000. Influence of air temperature on preference for color temperature of general lighting in the room. J Human-Environ System 4, 41-47.

Newsham, G., Arsenault, G., Veitch, J., Tosco, A.M. \& Duval, C. 2005. Task lighting effects on office worker satisfaction and performance. Leukos 1, 7-26.

van Ooijen, A.M.J., van Marken Lichtenbelt, W.D., van Steenhoven, A.A. \& Westerterp, K.R. 2007. Cold-induced heat production preceding shivering. Br J Nutr 93, 387.

Pandi-Perumal, S.R., Trakht, I., Srinivasan, V., Spence, D.W., Maestroni, G.J., Zisapel, N. \& Cardinali, D.P. 
2008. Physiological effects of melatonin: role of melatonin receptors and signal transduction pathways. Prog Neurobiol 85, 335-353.

Park, S.J. \& Tokura, H. 1998. Effects of different light intensities during the daytime on circadian rhythm of core temperature in humans. J Physiol Anthropol Appl Human Sci 17, 253-257.

Pritchett, D., Wulff, K., Olivier, P.L., Bannerman, D.M., Davies, K.E., Harrison, P.J., Peirson, S.N. \& Foster, R.G. 2012. Evaluating the links between schizophrenia and sleep and circadian rhythm disruption. I Neural Transm 119, 1061-1075.

Ranganath, G.S. 2008. Black-body radiation. Resonance 13, 115-133.

Reid, K.J., Santostasi, G., Baron, K.G., Wilson, J., Kang, J. \& Zee, P.C. 2014. Timing and intensity of light correlate with body weight in adults. PLOS ONE 9, e92251.

Romanovsky, A.A. 2007. Thermoregulation: some concepts have changed. Functional architecture of the thermoregulatory system. Am J Physiol Regul Integr Comp Physiol 292, R37-R46.

Ruger, M., Gordijn, M.C., Beersma, D.G., de Vries, B. \& Daan, S. 2005. Nasal versus temporal illumination of the human retina: effects on core body temperature, melatonin, and circadian phase. J Biol Rhythms 20, 60-70.

Ruger, M., Gordijn, M.C., Beersma, D.G., de Vries, B. \& Daan, S. 2006. Time-of-day-dependent effects of bright light exposure on human psychophysiology: comparison of daytime and nighttime exposure. Am J Physiol Regul Integr Comp Physiol 290, R1413-R1420.

Saarela, S. \& Reiter, R.J. 1994. Function of melatonin in thermoregulatory processes. Life Sci 54, 295-311.

Sahin, L., Wood, B.M., Plitnick, B. \& Figueiro, M.G. 2014. Daytime light exposure: effects on biomarkers, measures of alertness, and performance. Behav Brain Res 274C, 176-185.

Saper, C.B., Scammell, T.E. \& Lu, J. 2005. Hypothalamic regulation of sleep and circadian rhythms. Nature 437, 1257-1263.

Sato, M., Torlinska, T. \& Tokura, H. 2003. The effect of bright/dim light exposure during the daytime on rectal temperature and plasma glucose concentration in healthy women. Biol Rhythm Res 34, 413-422.

Sato, M., Sakaguchi, T. \& Morita, T. 2005. The effects of exposure in the morning to light of different color temperatures on the behavior of core temperature and melatonin secretion in humans. Biol Rhythm Res 36, 287-292.

Scheer, F.A., Pirovano, C., Van Someren, E.J. \& Buijs, R.M. 2005. Environmental light and suprachiasmatic nucleus interact in the regulation of body temperature. Neuroscience 132, 465-477.

Shamsul, B.M.T., Sia, C.C., Ng, Y.G. \& Karmegan, K. 2013. Effects of light's colour temperatures on visual comfort level, task performances, and alertness among students. Am J Publ Health Res 1, 159-165.

Shi, L. 2013. Effect of illumination and color temperature of lighting on human thermoregulation. J Shanghai Jiao Tong Univ 47, 1616-1620.
Smolders, K.C.H.J., de Kort, Y.A.W. \& Cluitmans, P.J.M. 2012. A higher illuminance induces alertness even during office hours: findings on subjective measures, task performance and heart rate measures. Physiol Behav 107, 7-16.

Takakura, J., Nishimura, T. \& Watanuki, S. 2013. Visual information without thermal energy may induce thermoregulatory-like cardiovascular responses. J Physiol Anthropol 32, 26.

Teramoto, Y., Tokura, H., Ohkura, K., Ohmasa, Y., Suho, S., Inoshiri, R. \& Masuda, M. 1996. Effects of different light intensities during the forenoon on the afternoon thermal sensation in the mild cold. J Therm Biol 21, 339-343.

Terron, M.P., Delgado-Adamez, J., Pariente, J.A., Barriga, C., Paredes, S.D. \& Rodriguez, A.B. 2013. Melatonin reduces body weight gain and increases nocturnal activity in male Wistar rats. Physiol Behav 118, 8-13.

Thapan, K., Arendt, J. \& Skene, D.J. 2001. An action spectrum for melatonin suppression: evidence for a novel nonrod, non-cone photoreceptor system in humans. J Physiol 535, 261-267.

Tokura, H., Yutani, M., Morita, T. \& Murakami, M. 1994. Effects of bright and dim light intensities during daytime upon circadian rhythm of core temperature in man. In: Temperature Regulation, pp. 285-289. Advances in Pharmacological Sciences, Birkhäuser Basel.

Veitch, J., Grifford, R. \& Hine, D.W. 1991. Demand characteristics and full spectrum lighting effects on performance and mood. J Environ Psychol 11, 87-95.

Wakamura, T. \& Tokura, H. 2000. The influence of bright light during the daytime upon circadian rhythm of core temperature and its implications for nocturnal sleep. Nurs Health Sci 2, 41-49.

Webb, A.R. 2006. Considerations for lighting in the built environment: non-visual effects of light. Energ Buildings $38,721-727$.

Winzen, J., Albers, F. \& Marggraf-Micheel, C. 2014. The influence of coloured light in the aircraft cabin on passenger thermal comfort. Lighting Res Technol 46, 465-475.

Xu, A.J. \& Labroo, A.A. 2014. Incandescent affect: turning on the hot emotional system with bright light. J Consumer Psychology 24, 207-216.

Yasukouchi, A., Yasukouchi, Y. \& Ishibashi, K. 2000. Effects of color temperature of fluorescent lamps on body temperature regulation in a moderately cold environment. J Physiol Anthropol Appl Human Sci 19, 125-134.

Zeitzer, J.M., Dijk, D.J., Kronauer, R., Brown, E. \& Czeisler, C. 2000. Sensitivity of the human circadian pacemaker to nocturnal light: melatonin phase resetting and suppression. J Physiol 526(Pt 3), 695-702.

Zhang, P. \& Tokura, H. 1999. Thermoregulatory responses in humans during exercise after exposure to two different lighting intensities. Eur J Appl Physiol 79, 285-289.

Zhong, C.B. \& Leonardelli, G.J. 2008. Cold and lonely: does social exclusion literally feel cold? Psychol Sci 19, 838-842.

Zigmond, M.J., Bloom, F.E., Landis, S.C., Roberts, J.L. \& Squire, L.R. 1999. Fundamental Neuroscience. Academic Press, San Diego, CA. 